\title{
Design and Fabrication of Fire Fighting Autonomous Robotic System Equipped with Sensitive Sensors for Fire Alarm and Detection, Avoidance Behaviour Mechanism and SMS Messaging Capability
}

Lexter J. Resullar, Angelou Joefred N. Congreso, Fernando Comandante, Floramyr P. Sarvida, Phd. \&

Engr. Gideon G. Buniel. MIT

Surigao del Norte National High School, Philippines.

DOI: http://doi.org/10.38177/AJBSR.2020.2404

Copyright: $\odot 2020$ Lexter J. Resullar et al. This is an open access article distributed under the terms of the Creative Commons Attribution License, which permits unrestricted use, distribution, and reproduction in any medium, provided the original author and source are credited.

\section{ABSTRACT}

Artificial intelligent systems applied to robots have been a part of our work environment but it is not only limited to industrial automation. Recently, fire fighting robots are developed to mitigate disaster during fire accidents. In this work, fire fighting robotic system equipped with sensitive flame sensors, avoidance mechanism, alarm and SMS capability is developed, designed and fabricated. Circuit design integrates several components to a microcontroller to successfully carry out its programmed task. The structural design of the chassis is to accommodate all components for optimum performance. The codes were adjusted to see what was most efficient and fit the task at hand. The Fire Fighting Robot with Alarm System has its featured components such as Flame Sensor, Smoke Sensor, Ultrasonic Sensor, Piezo Speaker, LED, and Global System for Mobile Module and Min Water Pump. Experimental results revealed that successful operation of the fabricated fire fighting robotic system take place. The optimal response time of the move stop was found to be $400 \mathrm{~ms}$ this suggests that the robotic system will start extinguishing the fire and automatically stop the pumping of water upon complete extinguishing of fire. Furthermore, the installed ultrasonic sensor successfully sent signal to the microcontroller to perform the avoidance mechanism of the robotic system from the obstacle. Likewise, the fire and smoke alarm detection as well as the SMS messaging capability was successfully activated upon the detection of fire and smoke. This successful fabrication of fire fighting robotic system will be a potential mechanism to fighting fire disaster.

Keywords: Fire fighting robot, Alarm system, Artificial intelligent, Autonomous, Microcontroller-based robotic system.

\section{Introduction}

\section{Background of the Study}

Robotics technology becomes more ubiquitous in recent industrial revolution. It is very important that artificial intelligent robots can readily interact with human with minimal control or even remotely controlled robots. Recently, human interactions with robots are no different than the interactions one might have with any piece of technological gadgets. It is more important to know that interactive interactions as well as artificial intelligent robots can perform task with minimal or no supervision by humans.

It has been reported that fire disaster will almost consume everything. Flame voraciously consumes almost anything it touches. In less than a minute a small flame can turn into a major fire. It only takes few minute for the thick black smoke to fill a property or establishment to be engulfed in flames. In a split of seconds, everything will be turned into ashes. To prevent the fire disaster to happen, a set of good practices will be implemented to reduce destruction caused by fire. Early detection and extinguishing are very important factors that can significantly reduce massive destruction. There are many available fire extinguishing systems in use today utilizing different methods and techniques. (1) In fact, there were patents available in fire extinguishing utilizing non-solid extinguishing materials. Furthermore, it is also widely known that every locality will create fire departments to address the fire disaster that may accidentally occur. All fire department around the country will only use the conventional way of fire extinguishing with more fireman human interventions. 
Scientists and engineers around the globe are working hard to develop a robotic system that will address the early detection and fast extinguishing of fire. To address this existing problem, robotic systems have been introduced to offer possible alternative solution to fire disasters. This technique attempts to reduce the risk of losing human life during fire disaster. There were reports also that robots have been deployed to extinguish fire but more requires human interactions. Moreover, there were previous reports also that were utilizing mobile robotics for firefighting and fire extinguishing. (2) The drawback of this robotic technology is that it only focuses on the hardware development but failed to include the automatic short message service (SMS) sent to the concerned party. In addition, there was no alarm system installed in their robotic system.

In this scientific project, the researchers develop, design and fabricate a fire fighting robotic system equipped with sensitive flame sensors, avoidance mechanism, alarm and SMS capability.

\section{Statement of the Problem}

The purpose of this science investigatory project is to develop, design and fabricate firefighting robotic system equipped with sensitive flame sensors, avoidance mechanism, alarm and SMS capability. In particular, the purpose of the study is to answer the following questions:

1. Will the circuitry designs for firefighting robotic system function?

2. Will the fabrication of the designed circuit work correctly?

3. Will the installed ultrasonic sensor function to avoid obstruction?

4. Does the installed fire alarm and detection system attached to the robot function properly?

5. Does the installed hardware capable of sending SMS to the concerned party in case of fire functions correctly?

6. Does the testing of the firefighting robotic system equipped with sensitive flame sensors, avoidance mechanism, alarm and SMS capability successful?

\section{Objectives of the Study}

The study aims to develop, design and fabricate firefighting robotic system equipped with sensitive flame sensors, avoidance mechanism, alarm and SMS capability. Specifically, this work aims to:

1. Design a circuitry capable of autonomously controlling firefighting robotic system equipped with sensitive flame sensors, avoidance mechanism, alarm and SMS capability.

2. Fabricate the designed circuitry for building a fire fighting robotic system equipped with sensitive flame sensors.

3. Install ultrasonic sensor for avoidance of obstructions.

4. Install a fire alarm and detection system attached to the robot.

5. Install hardware capable of sending SMS to the concern party in case of fire. 
6. Test the functionality of the firefighting robotic system equipped with sensitive flame sensors, avoidance mechanism, alarm and SMS capability.

\section{Null Hypotheses}

1. The circuitry designs for firefighting robotic system will not function

2. The fabrication of the designed circuit will not work correctly

3. The installed ultrasonic sensor will not function to avoid obstruction

4. The installed fire alarm and detection system attached to the robot do not function properly

5. The installed hardware capable of sending SMS to the concern party in case of fire do not function correctly

6. The testing of the firefighting robotic system equipped with sensitive flame sensors, avoidance mechanism, alarm and SMS capability is not successful

\section{Significance of the Study}

This study promotes a new idea of reducing flame disaster. The world has a new way to extinguish flame through innovating robotic system that will autonomously control and extinguish fire. It is potentially useful for future studies in developing an advanced and cutting edge robot which has benefits in mitigating flame and becomes equipped with the destruction of flame. All because of its unique features, the house and owner will be more secured. Therefore, this is a helpful contribution to mankind considering its help in reducing disaster risk. The alarm system installed will notify the authority or the owner that resulting to the decrease the number of fires in the country.

\section{Scope and Limitations of the Study}

The general purpose of this study was to introduce a timely technological fire fighting robot for reducing the risk of flame disaster. The study was inspired by this year's theme, "Utilizing Science Innovation, Promoting Disaster Risk Reduction". The study was conducted three months ago with a vision to integrate a new method of reducing the risk of disaster using this microcontroller unit based. The circuitry design of the firefighting robotic system equipped with sensitive flame sensors, avoidance mechanism, alarm and SMS capability was made to ensure the functionality of the robotic system. This work is limited only to develop, design and fabricate fire fighting robotic system equipped with sensitive flame sensors, avoidance mechanism, alarm and SMS capability. Specifications of the semiconductor devices are based on the required functionality of the robotic system. Furthermore, computer codes are made to address the specific demand of the robotic system. Only water is utilized in fire extinguishing. It is noted that this miniature work is intended only to extinguish small fire only. Huge fire source extinguishing is beyond the scope of this work. Likewise, the position of the water supply is fixed in a certain angle only. Height is also considered in extinguishing fire utilizing this miniature fire fighting robotic system. Optimization of the fabricated fire fighting robotic system is beyond the scope of this study. 


\section{Review of Related Literature}

This project entitled "Design and Fabrication of Fire Fighting Autonomous Robotic System Equipped with Sensitive Sensors for Fire Alarm and Detection, Avoidance Behaviour Mechanism and SMS Messaging Capability". The title was based on the functions and objectives of the study. However, this project was similarly alike to other robots but this innovative robot was the researchers own idea. The features were pondered by the researchers technically focusing on the components contributions when assembled as one robot. The Design and Fabrication of Fire Fighting Autonomous Robotic System Equipped with Sensitive Sensors for Fire Alarm and Detection, Avoidance Behaviour Mechanism and SMS Messaging Capability has additional features that make it unique to others. It was installed with an alarm system that notifies the owner that flame has occurred. Moreover, it has an auxiliary function like ultrasonic sensor, flame sensor and a smoke sensor that detects the flame combustion.

Robot is a machine that resembles a human being and mimics various complex tasks. Now, let us have a good look at existing fire fighting robots. The following robots below are the characteristic of the previous robot that have been similar with this robot project and used in the literature reviews:

A Fire Fighting Robot project was related to a project for extinguishing the flame which was published by Tushar Nandkishor Satbhai et al of E\&TC Department, Gangamai College of Engineering, Nagaon North Maharashtra University, Jalgaon, India. The controlling devices of the whole system were microcontrollers, wireless transceiver modules, water jet spray, DC motors, and buzzer were interfaced to Microcontroller. When the user fed the commands through a remote-controlled device, the microcontroller interfaced reads the command and sends relevant data with that command wirelessly using transceiver module. This data was received by the transceiver module on the robot and fed it to the microcontroller which acts accordingly on motors and pump. The complete system consists of two subsystems transmitter section and the receiver section. This project controls left, right, forward and backward movement of robot wirelessly within 500m range using $433 \mathrm{MHz}$ RF frequency. At the receiver side of robot PIC microcontroller was also used. The microcontroller takes command wirelessly transmitted by an RF transmitter. The need for a device that can detect and extinguish a flame on its own was long past due. ${ }^{3}$

The Shipboard Autonomous Flame Fighting Robot - was the first live test for SAFFiR and the first time a robot has ever fought a flame. Developed by roboticists at Virginia Polytechnic Institute and State University (Virginia Tech) in Blacksburg for the US Navy, SAFFiR was intended to be part of the Flame Fighting equipment of the future on board every Navy ship, tackling fires without risking human life. ${ }^{4}$ The RF-based Flame Fighting Robotic Vehicle; this Flame Fighting robot used RF technology for remote operation. This robot was loaded with a water tanker and a pump controlled through wireless communication to sprinkle water. For the desired operation, an 8051 microcontroller was used. ${ }^{5}$

The GSM-based Fire Fighting Robot, GSM modems have developed public utility products for mass communication. This GSM based Fire Fighting Robot was used to prevent flame in houses, offices, and shops. This robot moves in suffocated flame area in our house, offices, shopping malls, etc. This robot was capable of sensing 
flame using through IR sensors and then putting it off even in the absence of anyone. It then immediately sends the message to a concern person.

Pokey the Fire-Fighting Robot (USA) that was designed by Gerald Weed, Michael Schumacher, Shawn McVay and Jack Landes is a firefighting robot that made its way out of competitions, and became more "serious" than other systems. In there are detailed description of used equipment and basic algorithms of operating. Robots operating environment is a building, so the robot is equipped with necessary sensors, for example, with a line sensor, that could be not useful in conditions of dense smoke. ${ }^{6}$

Firefighting Robot is an American Trinity College development that was only on early-prototype stage (in 2008). It was supposed to this robot to be an autonomous device, with 15 minutes limited working time, after which it will return to the supply station. This approach is one of the best variants for firefighting in houses and non-industrial buildings. The main disadvantages are: the little working time and low-stock of "water". 7

Rolly Firefighter Robot is designed to search for a fire in a small floor plan of a house, extinguish the fire (by placing a cup over the LEDs), and then return to the front of the house. The navigation of the robot throughout the house is achieved by data provided by a line tracker and ultrasound transducers. The deployment of the extinguishing device is implemented with a custom arm controlled by servos. ${ }^{8}$

Fire Protection Robot is designed to enter a room and seek out a spot where there is extreme heat possibly due to a fire. Upon entering the room, the robot will once again use the color camera to pinpoint a spot where there is a large concentration of light. Once the robot has driven up to the light source, the heat sensor is activated to check and see if there is a large amount of heat being generated. If there is an excessive amount of heat generated, the fan is turned on and rotated quickly with a servo motor to put out the flame. If the flame is not put out the fan will turn on again and continue to blow on the flame. Once the flame is extinguished, the robot leaves the home. ${ }^{9}$

The "Autonomous Mobile Robot: Recognize and Response to fire" project will discuss about the development of a mobile robot which is can be train and control an autonomous robot that has a multifunction. The robot acquires basic navigation skills as well as the ability to detect a fire and to extinguish it. This robot is controlled by a microcontroller PIC16F84A and supported by RC circuits as driver for DC motors and other electronic components. This robot equipped with fire sensor that can be expand and attract so it can recognize and response to fire to operating water pump system. The battery monitoring circuit also equipped in this robot to make an easier to monitoring the overall robot battery power. ${ }^{10}$

\section{Methodology}

\section{Component Structure Design}

The project is controlled by Arduino Mega 2560, a microcontroller where different sensors are connected. This project uses two (4) SLB-1674 7.4V batteries to dissipate required and enough power to all the components of the robot. In addition to the two, the project also uses Four (4) decelerated 280 RPM DC motors extendable up to 9 wheels if needed that are controlled by L298 H-Bridge Motor Driver. The researchers also used different sensors to detect flame like flame sensors and smoke sensor. The presence of ultrasonic sensor was needed for the 
avoidance of obstacles. And the presence of the piezo speaker and light-emitting diode (LED) will stand as alarm system while the GSM/GPRS works in notifying through SMS to the owner. All the mentioned components above were connected to respective boards and modules where all grounds were connected in a common and 5 to 12 volts were in common.

The succeeding part of this project will introduce the different components that were used in building the robot.

\section{Equipment/ Material}

Soldering Iron - Arduino Mega 2560

Lead - Ultrasonic Sensor

Glue Sticks/ Glue Gun - Connecting Wires

Screw Driver - Smoke Sensor

Pliers - Flame Sensor

Screws - Motors

Electrical Tape - Wheels

Grinder - 180 Degree Servo Motor

Zip Tie - Switch/Button

Nuts and Bolts - Piezo Speaker

GSM/GPRS Module - Resistor

Safety Goggles - Battery

Safety Gloves - Motor Driver

Cutter - Electric Drill

LED

\section{Component Design Specification}

This Fire Fighting Robot was a combination of different components ordered domestically. The microcontroller accepts inputs from the components mainly the sensors and interprets it using the code written using Arduino IDE. The system works by putting the components altogether. On this project, the researchers use one Arduino Mega 2560 because of the availability of pins in a single board. The team uses different sensors that Arduino Mega 2560 can accommodate entirely.

The boards were divided so that sensors can work properly with their analog and digital pins properly connected. Arduino board was connected with Ultrasonic Sensor, Flame Sensor, Smoke Sensor, Piezo Speaker and GSM Module, Motor Drivers, Water Pump, Light-Emitting Diode (LED), Buzzer, DC Motors and Servo. 
The system needs a $12 \mathrm{~V}$ power supply to power the connected motors and pumps and $5 \mathrm{~V}$ for all the sensors connected. However, GSM/GPRS module requires external 9V supply. The functionalities and detailed information about the components used and the definition of each were as follows:

1. Arduino Mega 2560- is a microcontroller board based on the ATmega2560 (datasheet). It has 54 digital input/output pins (of which 15 can be used as PWM outputs), 16 analog inputs, 4 UARTs (hardware serial ports), a $16 \mathrm{MHz}$ crystal oscillator, a USB connection, a power jack, an ICSP header, and a reset button.

The specifications of microcontroller are as follows:

- Microcontroller: ATmega256

- Operating Voltage: $5 \mathrm{~V}$

- Input Voltage (recommended): 7-12V

- Input Voltage (limits): 6-20V

- Digital I/O Pins: 54 (of which 14 provide PWM output)

- Analog Input Pins: 16

- DC Current per I/O Pin: $40 \mathrm{~mA}$

- DC Current for $3.3 \mathrm{~V}$ Pin: $50 \mathrm{~mA}$

- Flash Memory: 256 KB of which 8 KB used by bootloader

- SRAM: $8 K B$

- EEPROM: $4 \mathrm{~KB}$

- Clock Speed: $16 \mathrm{MHz}$

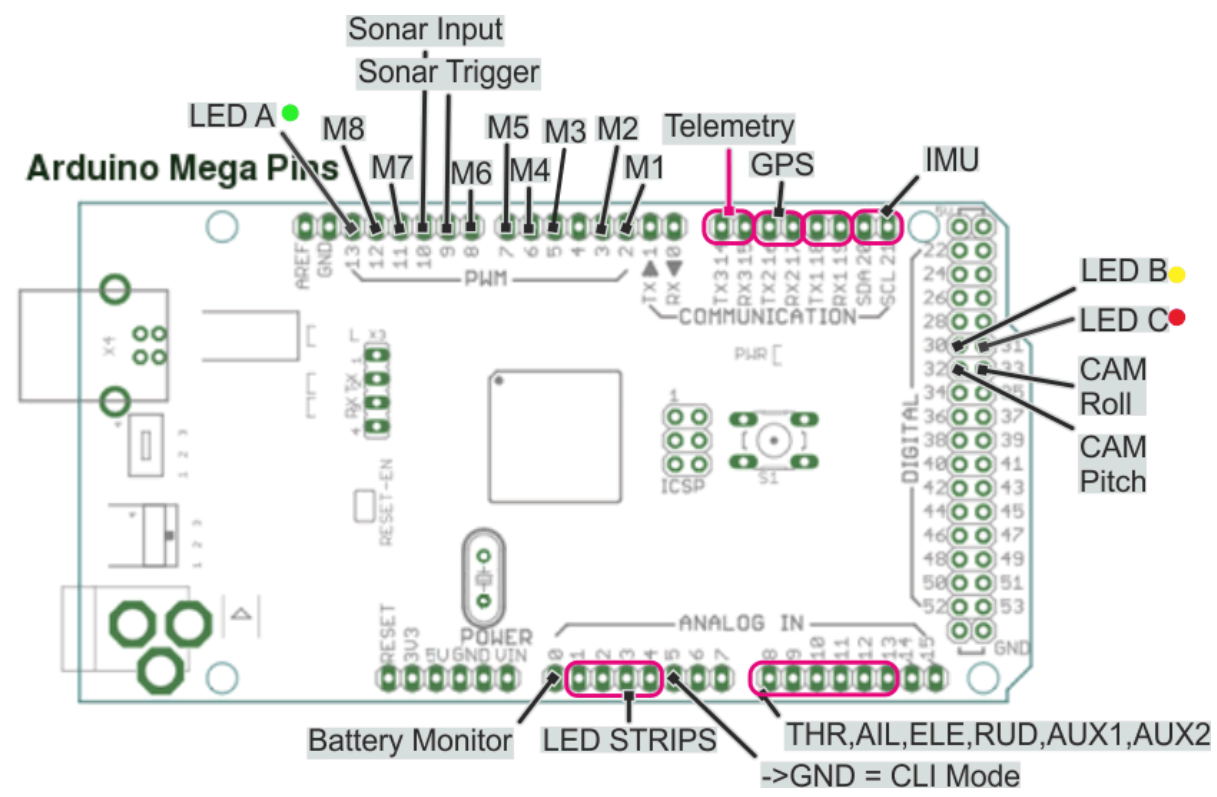

FIGURE 1.0 GIZDUINO VERSION 5 MAJOR COMPONENTS 


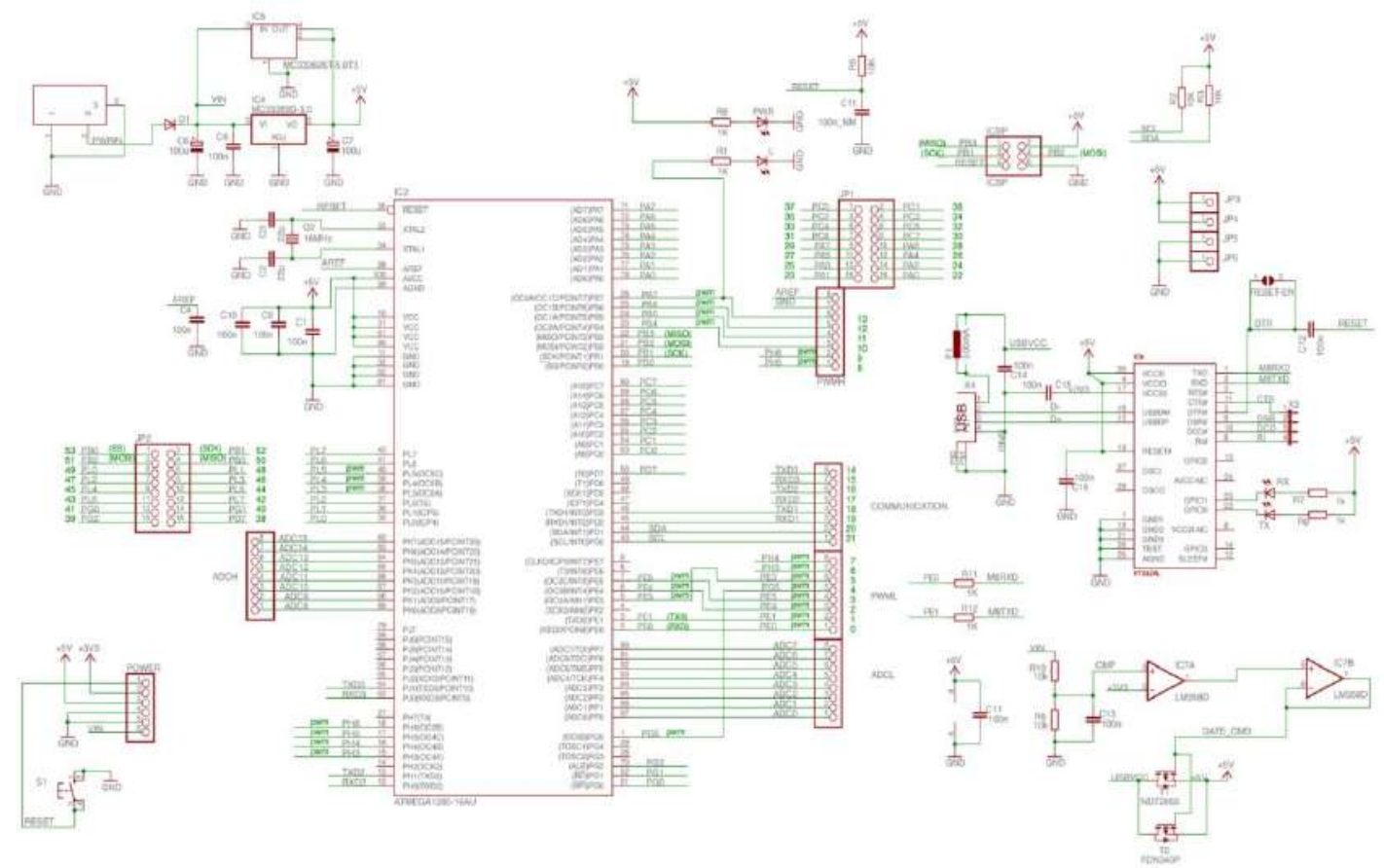

FIGURE 1.1 SCHEMATIC DIAGRAM OF ARDUINO MEGA 2560

2. Flame Sensor Module - a flame sensor module that detects flame or a light source of a wavelength in the range of $760 \mathrm{~nm}-1100 \mathrm{~nm}$ interfacing with Arduino board's MCU. By reading the Digital output of the sensor, 0 - if there's a flame, 1 - no flame detected.

The specifications of flame sensor module are as follows:

- Detection Distance: 1 meter (max sensitive adjustment)

- Detection Angle: 60 Degrees

- Operating Voltage: +5VDC

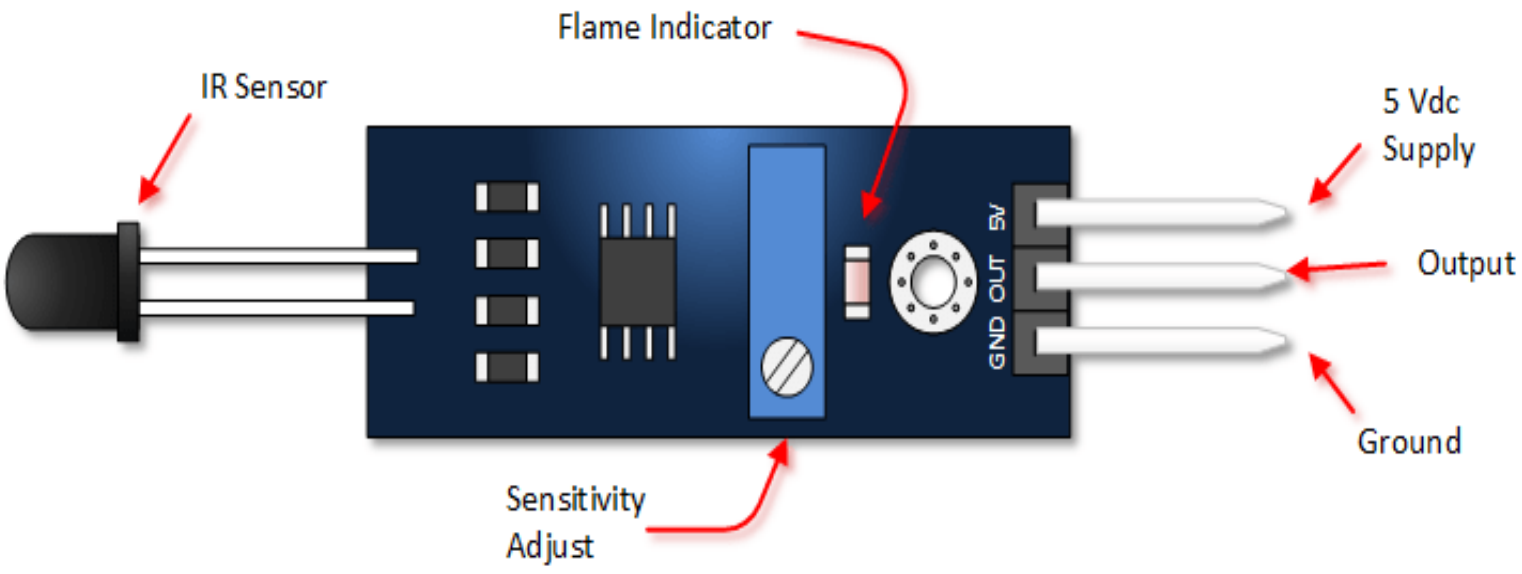

FIGURE 2.0 FLAME SENSOR MAJOR PARTS 


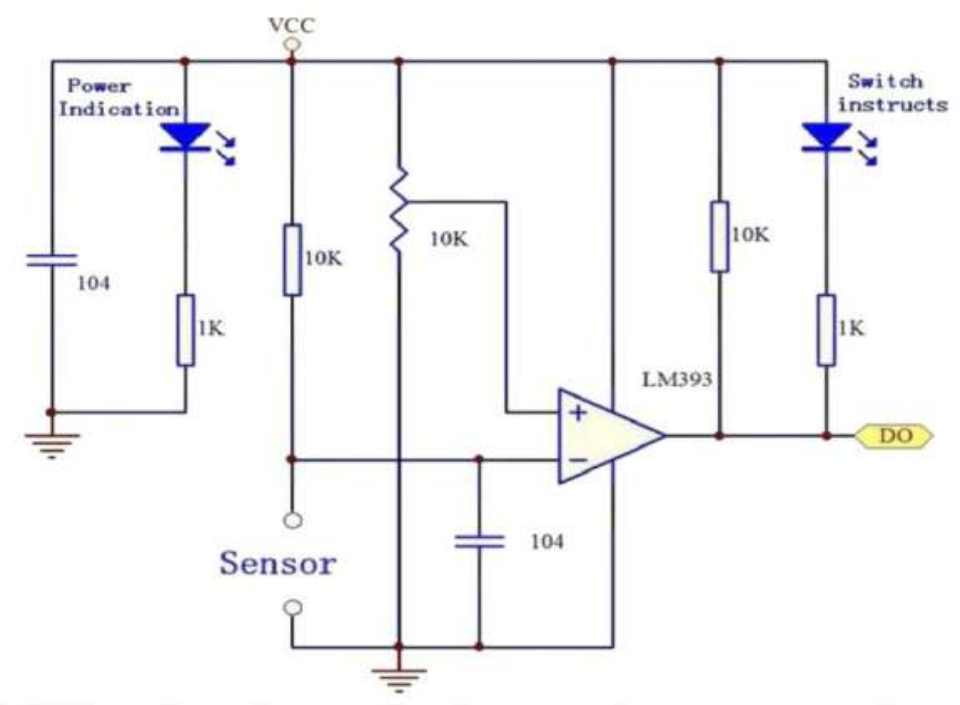

FIGURE 2.1 SCHEMATIC DIAGRAM OF FLAME SENSOR MODULE

3. Smoke Sensor - the MQ-2 Gas Sensor module detects gas leakage in home and industry. The MQ series of gas sensors use a small heater inside with an electrochemical sensor. They are sensitive to a range of gasses and are used indoors at room temperature. The output is an analog signal and can be read with an analog input of the Arduino. The MQ2 has an electrochemical sensor, which changes its resistance for different concentrations of varied gases. They are useful in gas leakage detection of LPG, propane, methane, i-butane, alcohol, Hydrogen, and smoke.

The specifications of Smoke Sensor are as follows:

- Working Voltage: $4.9 \mathrm{~V}$ to $5.1 \mathrm{~V}$

- Heating consumption: $0.5 \mathrm{~mW}$ to $800 \mathrm{~mW}$

- Load resistance: Adjustable

- Heater resistance: $33 \Omega$

- Sensing Resistance: $3 \mathrm{k} \Omega$ to $30 \mathrm{k} \Omega$

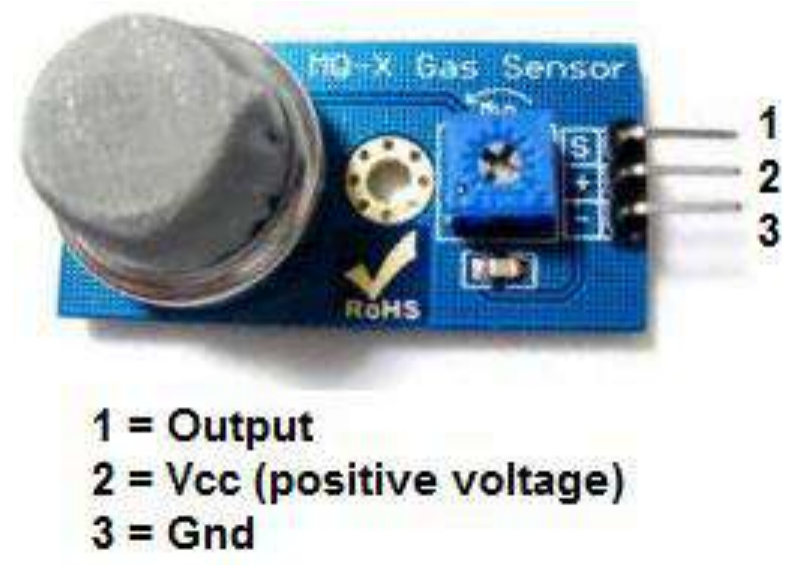

FIGURE 3.0 SMOKE SENSOR MAJOR PARTS 


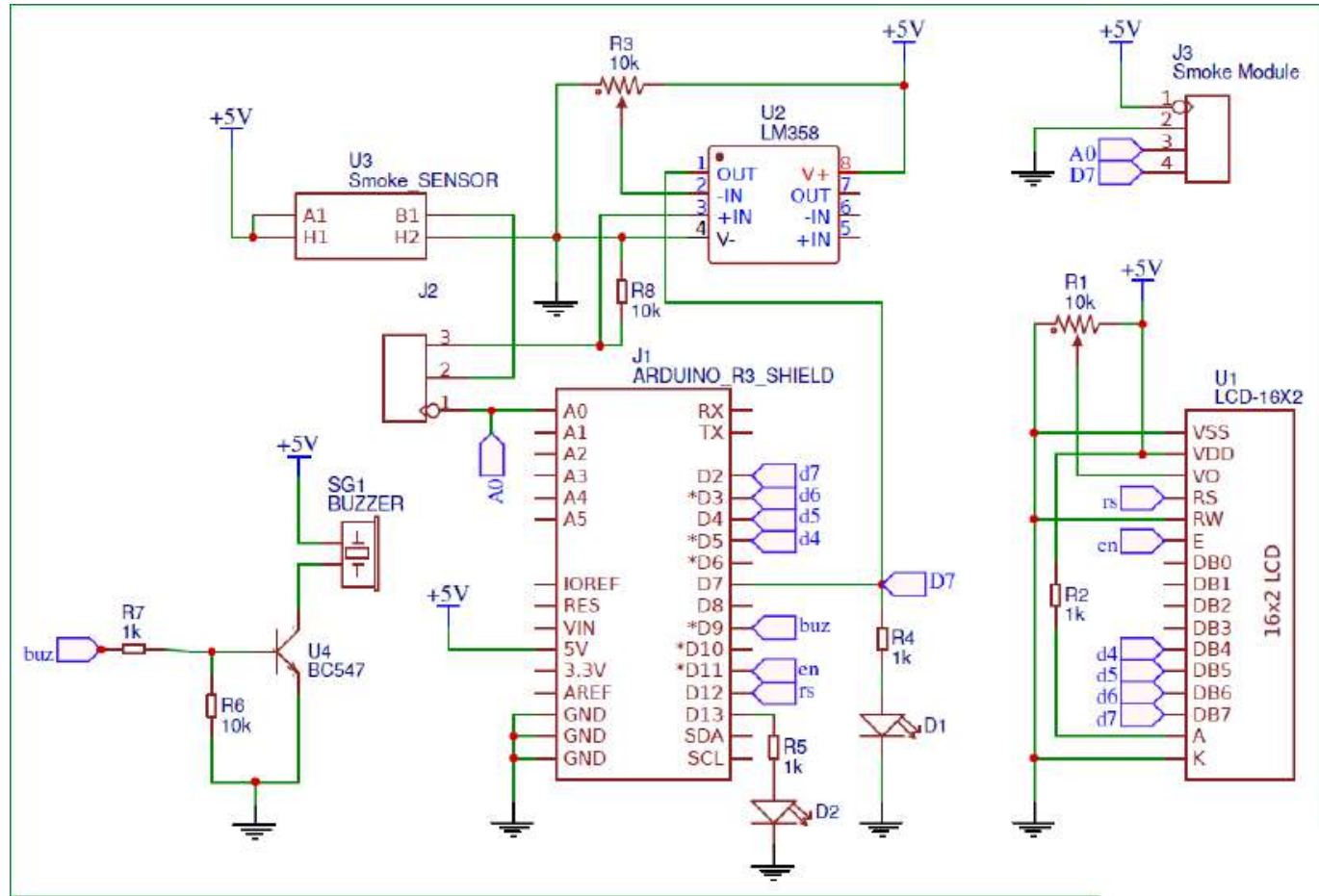

FIGURE 3.1 SMOKE SENSOR CIRCUIT DIAGRAM

4. GSM SIM900A Modem- is built with Dual Band GSM/GPRS based SIM900A modem from SIMCOM. It works on frequencies 900/ $1800 \mathrm{MHz}$. SIM900A can search these two bands automatically. The frequency bands can also be set by AT Commands. The baud rate is configurable from 1200-115200 through AT command. The GSM/GPRS Modem is having internal TCP/IP stack to enable you to connect with internet via GPRS. SIM900A is an ultra-compact and reliable wireless module. This is a complete GSM/GPRS module in a SMT type and designed with a very powerful single-chip processor integrating AMR926EJ-S core, allowing you to benefit from small dimensions and cost-effective solutions.

The specifications of GSM SIM900A Modem module are as follows:

- Dual-Band 900/ $1800 \mathrm{MHz}$

- GPRS multi-slot class 10/8GPRS mobile station class B

- $\quad$ Compliant to GSM phase $2 / 2+$

- Dimensions: $24 * 24 * 3 \mathrm{~mm}$

- Weight: $3.4 \mathrm{~g}$

- Supply voltage range: $5 \mathrm{~V}$

- Low power consumption: $1.5 \mathrm{~mA}$ (sleep mode)

- Operation temperature: $-40^{\circ} \mathrm{C}$ to $+85^{\circ}$ 


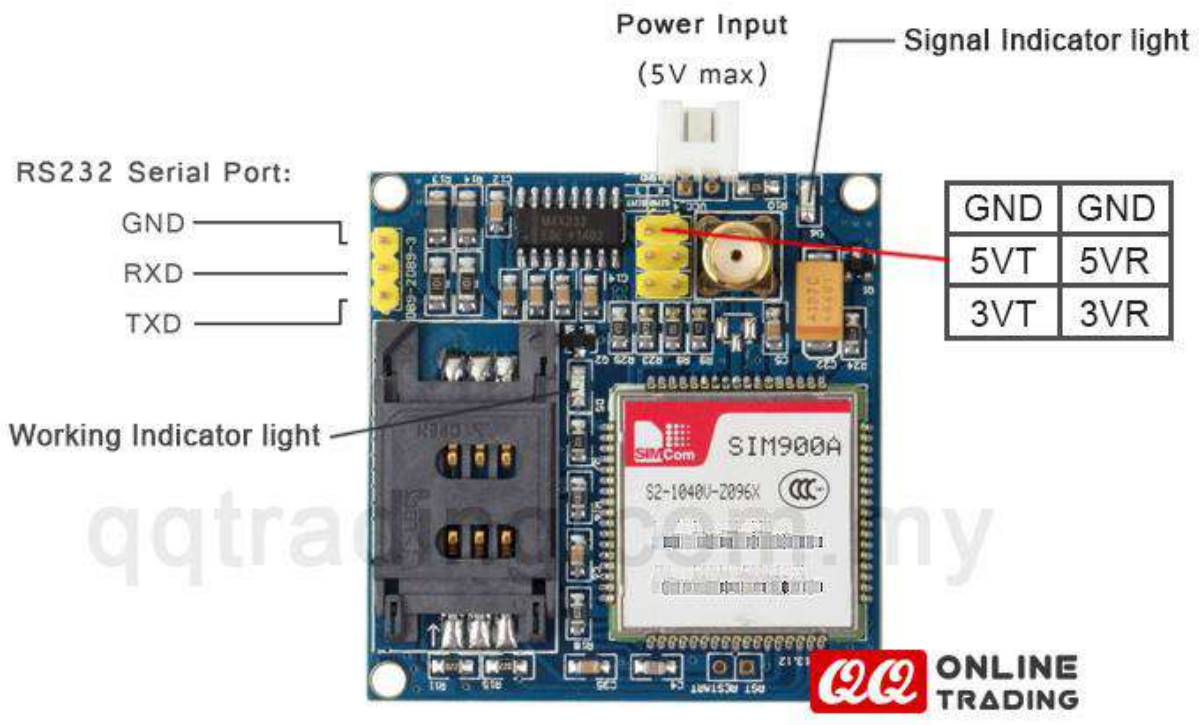

FIGURE 4.0 PARTS PLACEMENT OF GSM (SIM900A)

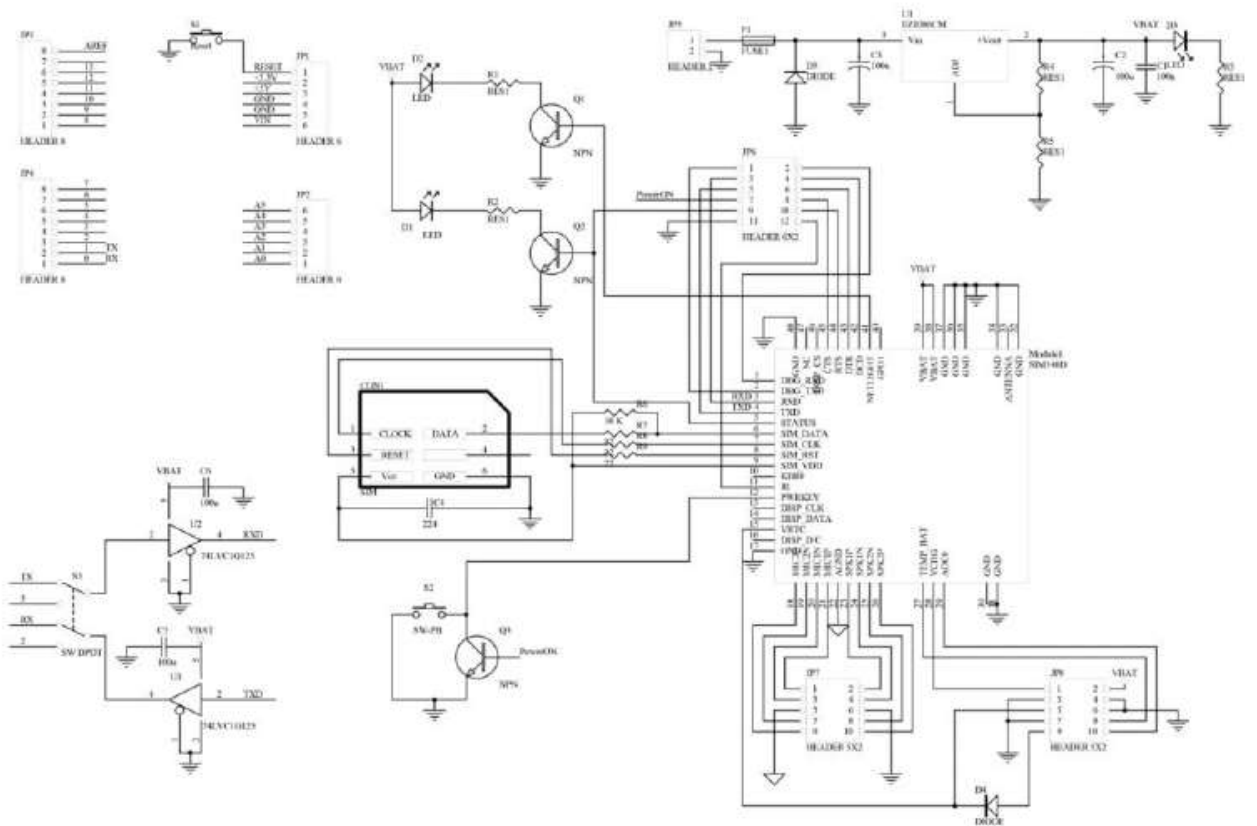

FIGURE 4.1 SCHEMATIC DIAGRAM OF GSM SHIELD (SIM900A)

5. L298N Double H-Bridge DC Stepper Motor Driver - allows you to control the speed and direction of DC motors or control one bipolar stepper motor with ease. A main driver chip with a strong driving capability, low heat, anti-interference ability.

The specifications of L298N Double H-Bridge DC Stepper Motor-Driver are as follows:

- Input Supply Voltage: 7V -12VDC

- Logic Voltage: 5V, 0A $~ 0.36 \mathrm{~A}$

- Maximum Power: 25W 


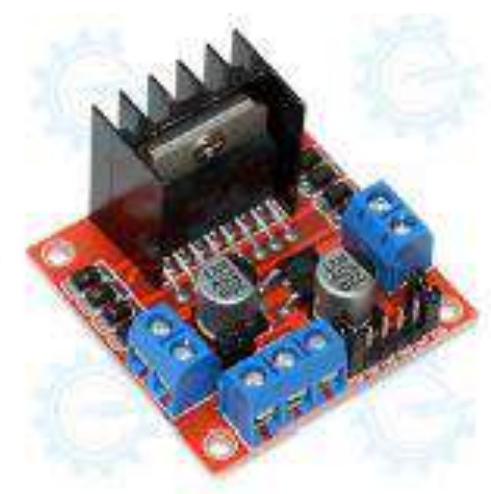

FIGURE 5.0 L298N DOUBLE H-BRIDGE DC STEPPER MOTOR DRIVER

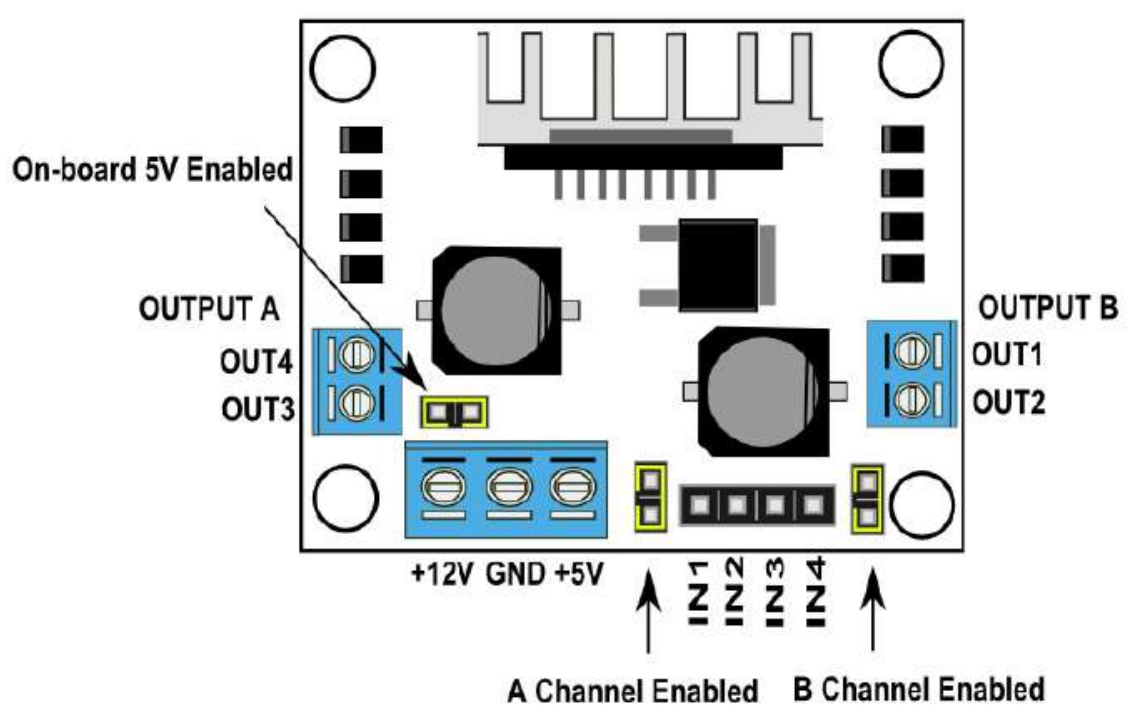

FIGURE 5.1 MAJOR PARTS OF L298N DOUBLE H-BRIDGE DC STEPPER MOTOR DRIVER

6. HC-SR04 Ultrasonic Sensor- ultrasonic sensor measures the distance of an object by using ultrasonic waves. The sensor sends out an ultrasonic wave and receives the wave reflected back from the object.

The specifications of HC-SR04 Ultrasonic Sensor are as follows:

- Working Voltage: DC 5V

- Working Current: $15 \mathrm{~mA}$

- Working Frequency: $40 \mathrm{~Hz}$

- Max Range: $4 \mathrm{~m}$

- Min Range: $2 \mathrm{~cm}$

- Measuring Angle: 15 degree

- Trigger Input Signal: $10 \mu$ STTL pulse

- Echo Output Signal Input TTL lever signal and the range in proportion 


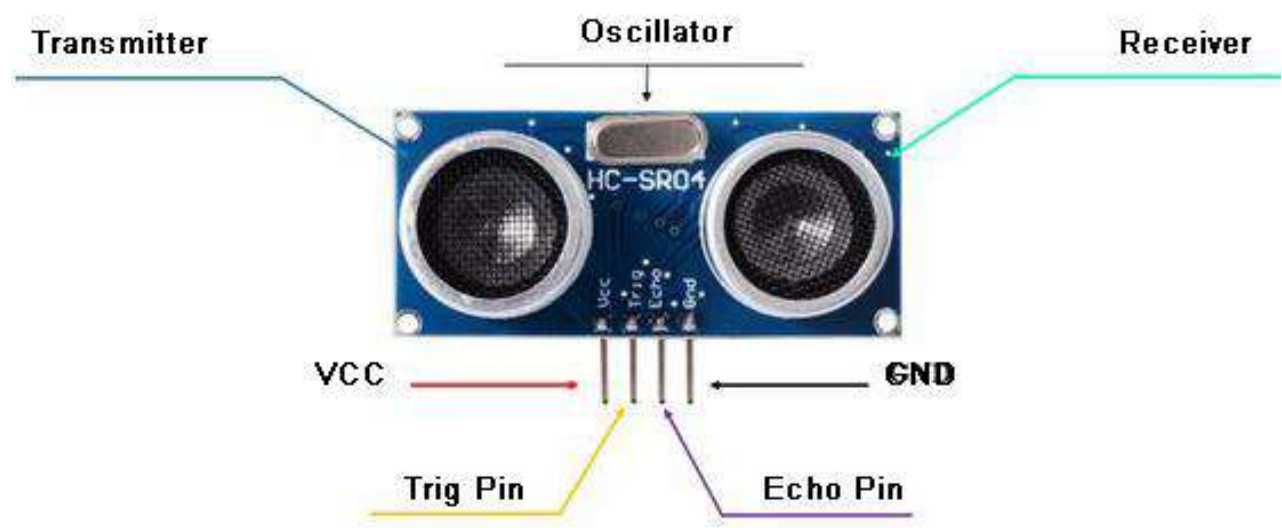

FIGURE 6.0 MAJOR PARTS OF HC-SR04 ULTRASONIC SENSOR

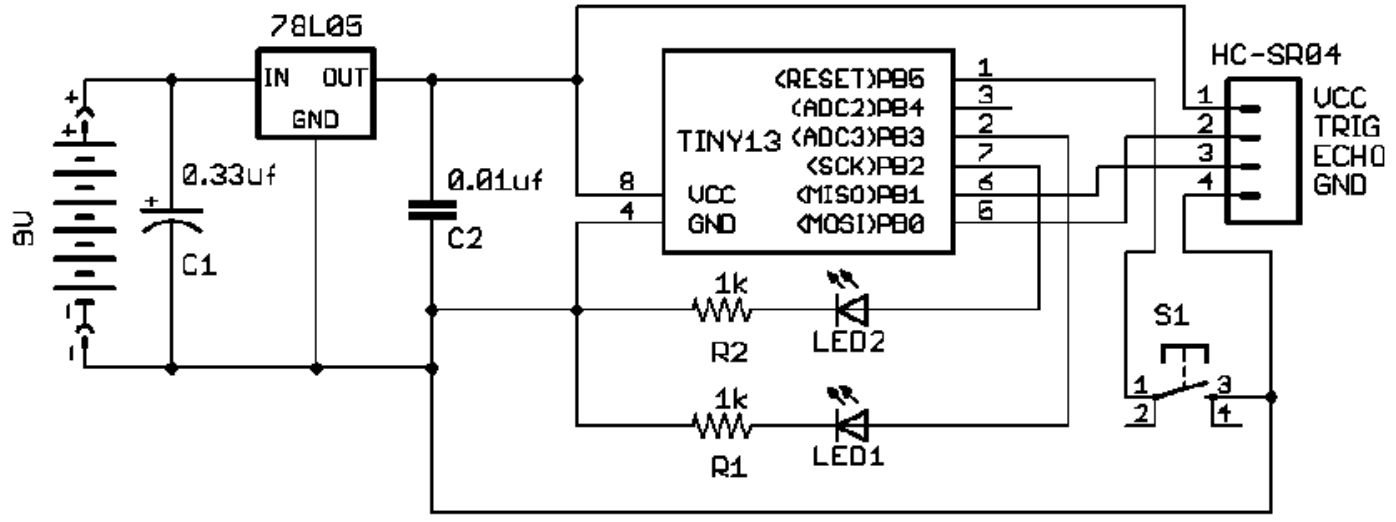

FIGURE 6.1 SCHEMATIC DIAGRAM OF HC-SR04 ULTRASONIC SENSOR

7. 12V Submersible DC Water Pump - a device that increases the pressure of a fluid or to create a vacuum in an enclosed space by the removal of a gas. The centrifugal pump consists basically of a rotating device, called an impeller, inside a casing. The fluid to be pumped enters the casing near the shaft of the impeller. Vanes attached to the spinning impeller give the fluid a high velocity so that it can move through an outlet. The reciprocating pump moves a fluid by using a piston that travels back and forth in a cylinder with valves to help control the flow direction. It uses electricity to move the fluid.

The specifications of 12V Submersible DC Water Pump are as follows:

- Type: mini water pump

- Pump rate: 3 liters per minute

- Power: 6V DC

- Current: 1.2A @6V,2.0A @ 9V DC

- Connection: 2 wire

- Nozzle Inlet connector outer diameter: $18 \mathrm{~mm}$

- Nozzle Outlet connector inner diameter: $6.5 \mathrm{~mm}$ 


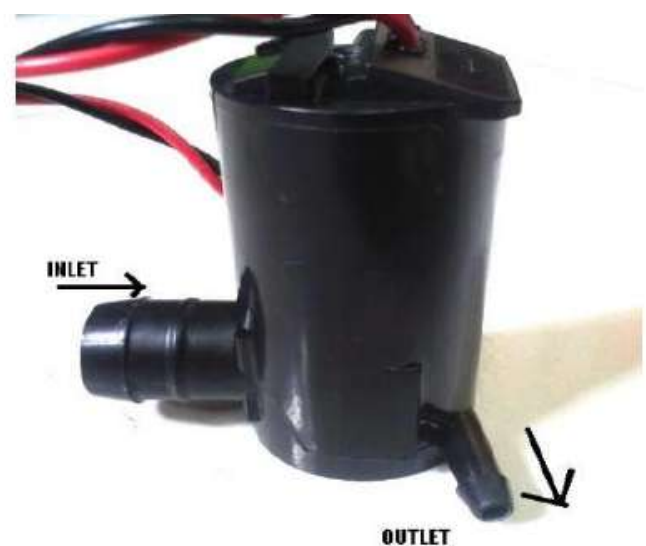

FIGURE 7.0 MAJOR PARTS OF 12V SUBMERSIBLE DC WATER PUMP
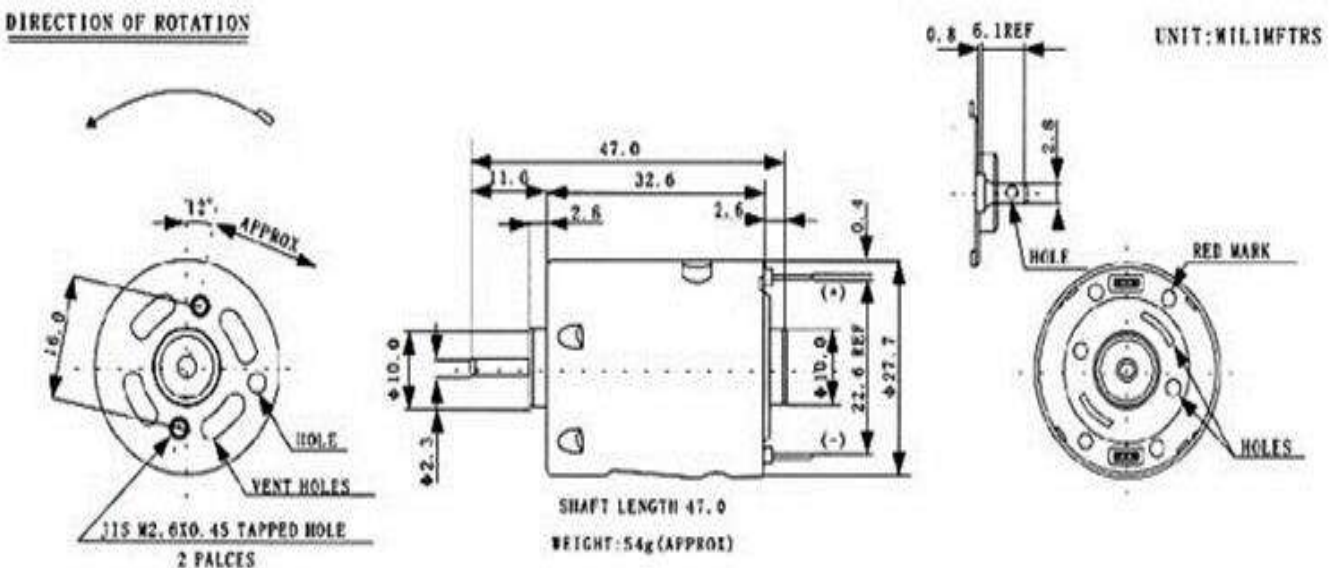

FIGURE 7.1 SCHEMATIC DIAGRAM OF 12V SUBMERSIBLE DC WATER PUMP

8. KY-016 5mm RGB Light-Emitting Diode (LED) - this module consists of a 5mm RGB LED and three $150 \Omega$ limiting resistors to prevent burnout. Adjusting the PWM signal on each color pin will result in different colors.

The specifications of KY-016 5mm RGB Light-Emitting Diode (LED) are as follows:

- Operating Voltage: $5 \mathrm{~V}$

- LED drive mode: Common cathode driver

- LED diameter: $5 \mathrm{~mm}$

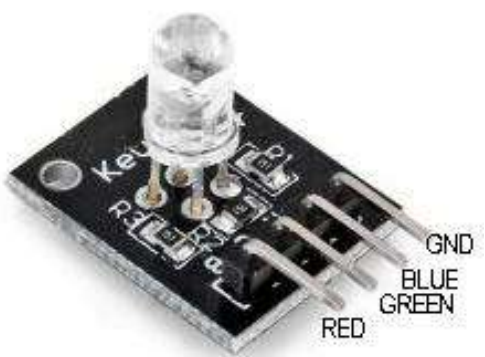

FIGURE 8.0 MAJOR PARTS OF 5 MM (LED) 
Asian Journal of Basic Science \& Research

Volume 2, Issue 4, Pages 21-51, October-December 2020

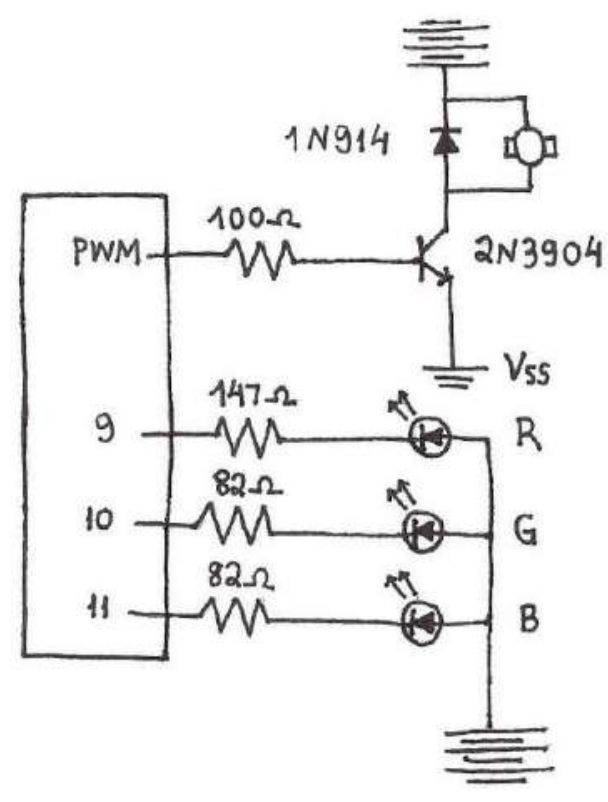

FIGURE 8.1 WIRING DIAGRAM OF KY-016 5MM RGB LED

9. Digital Servo SG90 (180?) - a tiny and lightweight with high output power servo that can rotate approximately 180 degrees (90 in each direction).

The specifications of Digital Servo SG90 (180?) are as follows:

- Weight: $9 \mathrm{~g}$

- Dimension: 22.2 x 11.8 x $31 \mathrm{~mm}$ approx.

- Stall torque: $1.8 \mathrm{kgf} \cdot \mathrm{cm}$

- Operating speed: $0.1 \mathrm{~s} / 60$ degree

- Operating voltage: $4.8 \mathrm{~V}(\sim 5 \mathrm{~V})$

- Dead bandwidth: $10 \mu \mathrm{s}$

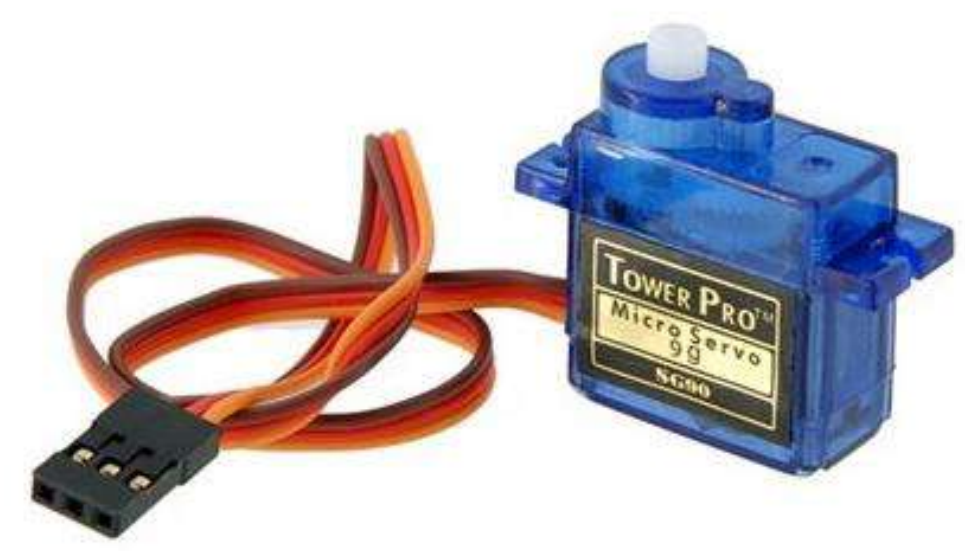

FIGURE 9.0 DIGITAL SERVO SG90 (180?) 
10. DC Motor- is any of a class of rotary electrical machines that converts direct current electrical energy into mechanical energy.

The specifications of DC Motor are as follows:

- Motor Voltage: 3 - $12 \mathrm{~V}$

- Motor Current: $70 \mathrm{~mA}$ (typical) - $250 \mathrm{~mA}(\max )$

- Speed: up to $170 \mathrm{RPM}$

- Torque: up to $0.8 \mathrm{Kg}$

- Gear Ration: 1:48

- Wheel Diameter: $66 \mathrm{~mm}$

- Wheel Width: $27 \mathrm{~mm}$

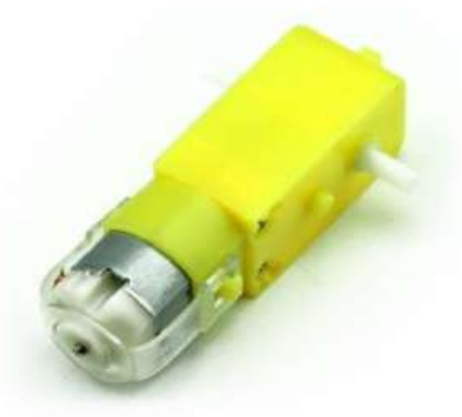

\section{FIGURE 10.0 DC MOTOR}

11. 5v Buzzer Piezo Speaker - an audio signaling device that has PWM output frequency and duration to produce different tones and beats according to the code.

The specifications of 5V Buzzer Piezo Speaker are as follows:

- Operating voltage: $3.3-5.2 \mathrm{VDC}$

- Operating Current: $25 \mathrm{~mA}(\max )$

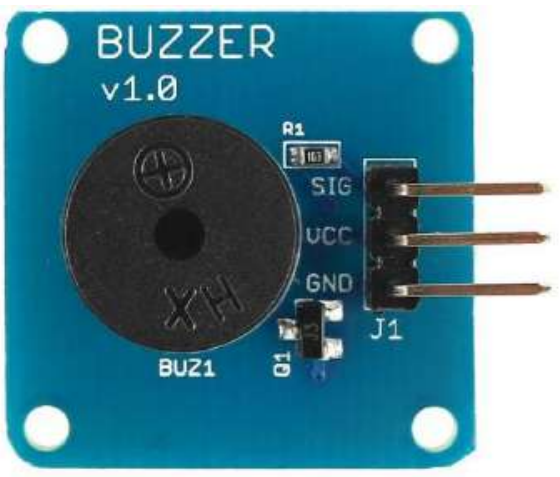

FIGURE 11.0 5v BUZZER PIEZO SPEAKER 


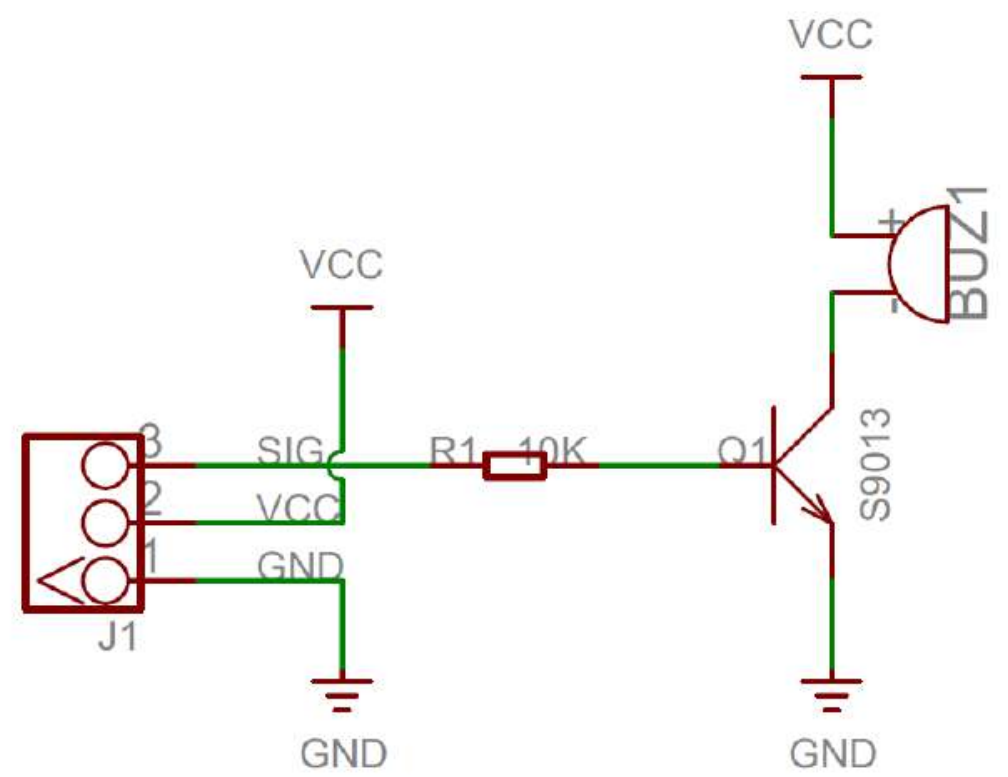

FIGURE 11.1 5v BUZZER PIEZO SPEAKER SCHEMATIC DIAGRAM

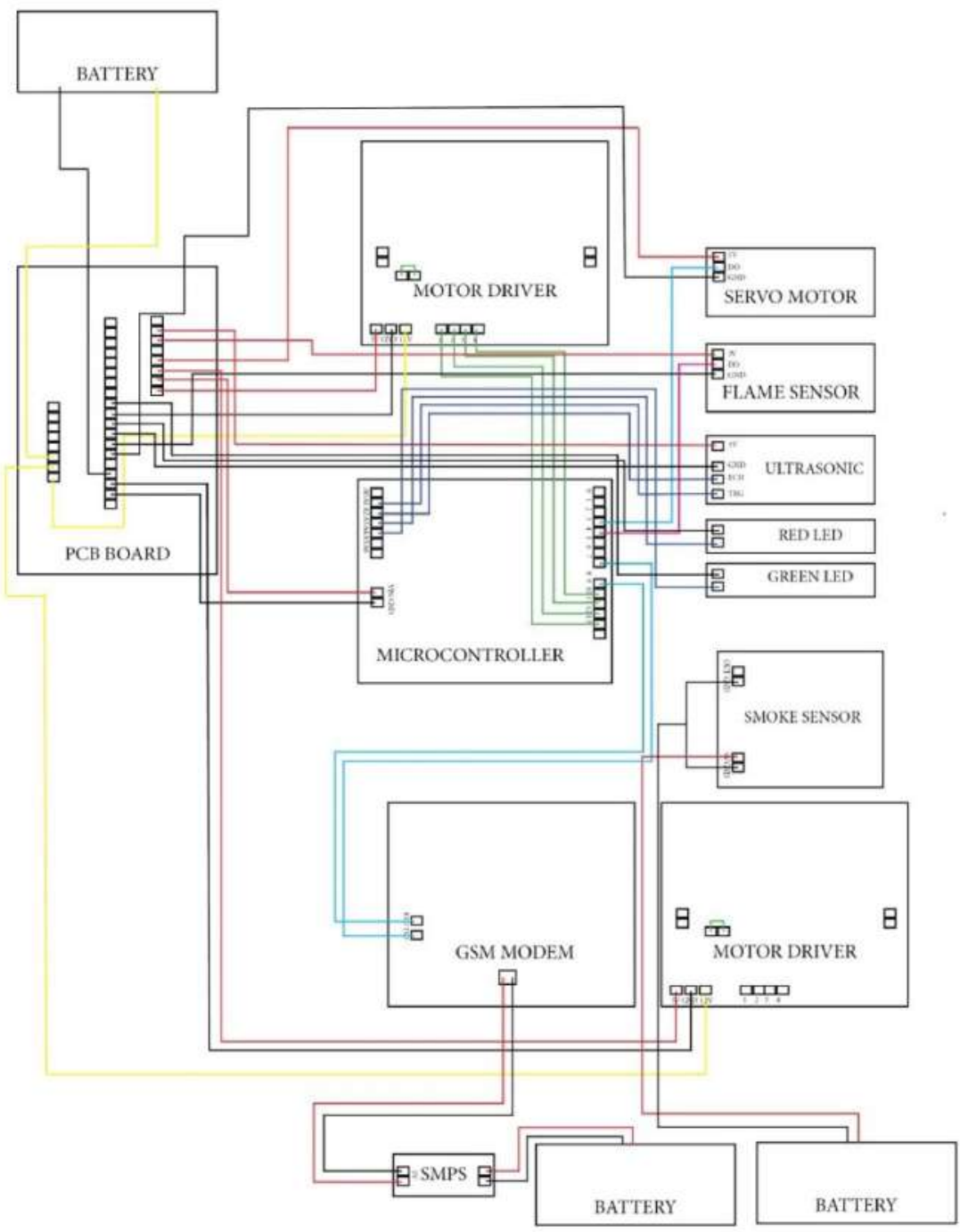

FIGURE 12.0 SCHEMATIC DIAGRAM FOR PIN CONNECTIONS 


\section{General Procedures}

\section{Planning}

Planning required all members of the team to brainstorm on what features must be added to the robot, what would the robot look like, what materials should be used for the robot, what would be the ideal dimensions of the robot and most importantly what would be the purpose of the robot. Furthermore, risk and safety precautions are considered since it demands handwork. Physical risk is susceptible to all the types of risks. In assembling the robot, the researchers categorized the hazard material into two: the hazardous chemicals and the hazardous devices. The hazardous chemicals that are used by the researchers are the following epoxy adhesive, glue stick, and lead. The hazardous materials that the researchers utilized are drill, soldering iron, cutter, glue gun, pliers, screws, bolts, and nuts. Hazardous material is any item or agent which has the potential to cause harm to humans, animals, or the environment, either by it or through interaction with other factors. Precautionary measures were taken to prevent the danger of researchers' welfare. Wearing gloves, goggles, and mask are the precautionary measures to keep away the researchers to harm and threats. Since programming was a prerequisite for robotics, all members had to do extensive research while having constant guidance from the consultant involved. We then had to decide on the logic flow that the robot would use to deliver its functions efficiently and smoothly.

\section{Fabrication of the Robot}

The dimension of the robot is $28 * 18 * 10$ centimeters (length*width*height). The material used for the platform is methyl methacrylate "cast acrylic" due to its lightweight, electrical insulating property, strength and resistance to cracking. The main shape of the platform is rectangle in order to fully utilize the space where the components will be placed. There are two main levels: the first level where components occupied and the second level is where water was placed. The second level was supported by threaded rod. Threaded rod gives the ability to adjust the height of the second level if the components will be rearranged have to spend the time or money to cut out a new design These materials are chosen to be used because they are lightweight and durable, but most importantly, available. We used steel epoxy as adhesive agent to assemble chassis and finished with nuts and bolts for security. The motors were then placed inside the chassis with the wheels protruding to allow for ground security. Other components inside the chassis are the Arduino, motor drivers, and GSM module. Outside the chassis are the sensors and servo motors, mini water pump, smoke sensor, flame sensors, and ultrasonic sensors are placed strategically for optimum performance.

\section{Input Design}

All inputs are data from the sensors being fed to the microcontroller for it to create decisions. Basically, all sensors are the inputs.

\section{Output Design}

Outputs actuate the decision made by the microcontroller using the data generated or gathered by the input. There are three forms of output involved in the robot, the Maneuver Output, the Servo Output. 
1. Maneuver Output

This output involves the DC motors connected to the motor driver that mobilizes the robot. They activate according to the decisions made by the microcontroller.

2. Servo Output

The servo output activates once the ultrasonic sensor detects an obstacle within its field of vision. The servo motor is what helps the ultrasonic to look left or right and find a clear path.

\section{Alarm Output}

The components involved in this output are the red LED light, piezo speaker, and the GSM module.

\section{Subsystems Design}

There are three subsystems integrated within the robot, namely the Fire Extinguishing Subsystem, Obstacle Avoidance Subsystem and the Alarm Subsystem. Successful integration of these three subsystems is the key to making the robot work.

\section{Fire Extinguishing Subsystem}

This subsystem involves the Maneuver Output, Flame Sensor, and the mini water pump. When fire is detected, the microcontroller gives instruction to the Maneuver Output to approach the fire, once close enough (fire proximity is determined by time delay) the water pump is activated to extinguish the fire. However, when there is no fire detected directly within its field of vision, the microcontroller unit will instruct the Maneuver Output rotate a full 360 degrees to survey its vicinity, when fire is detected during this survey, it will be approached, when there is still none detected, it will move forward for 700 milliseconds.

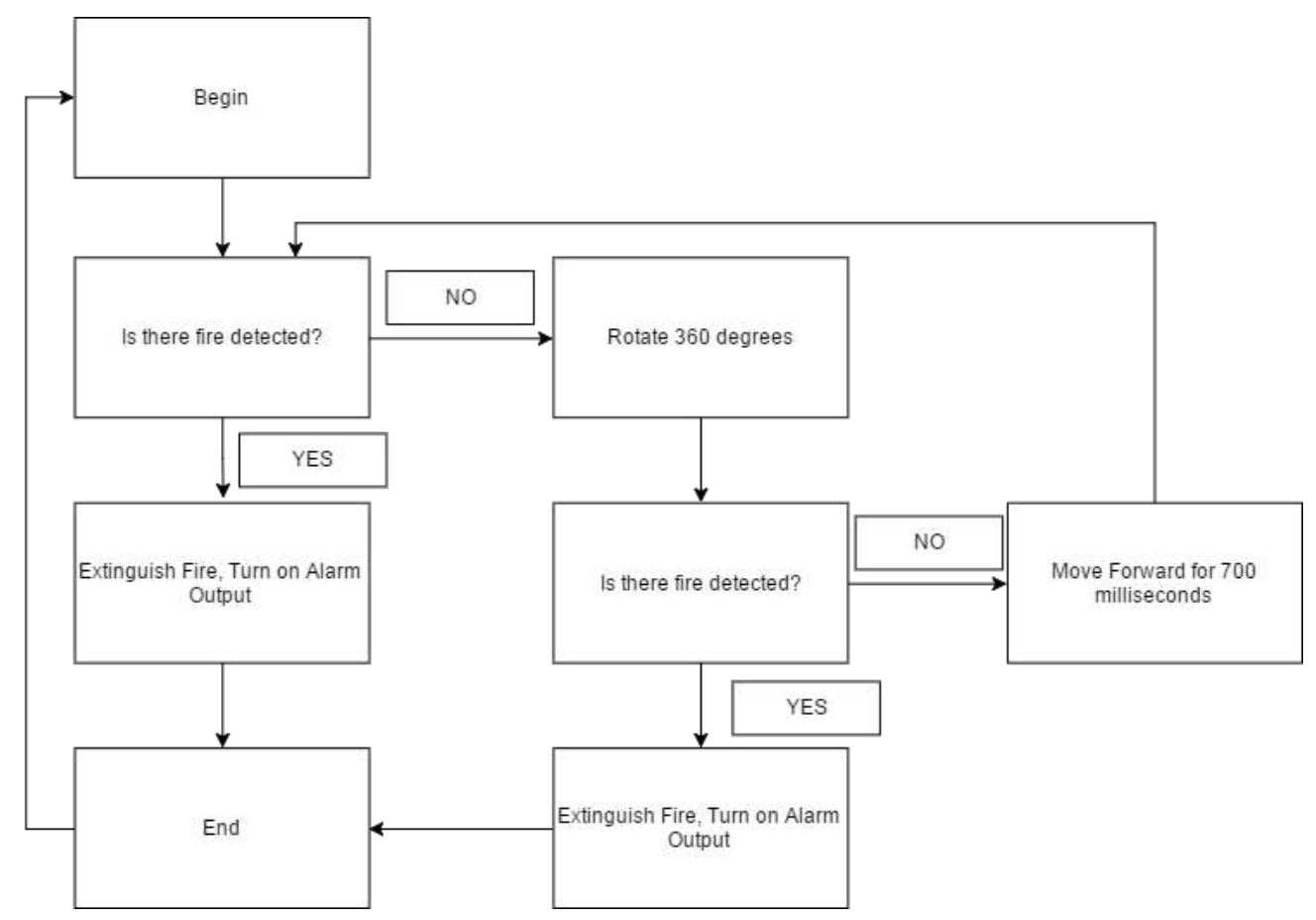

FIGURE 13.0 FIRE EXTINGUISHING SUBSYSTEM 
TABLE 1.0 EFFICIENCY TEST DESIGN FOR FIRE EXTINGUISHING SUBSYSTEM

\begin{tabular}{|c|c|c|c|c|l|l|}
\hline \multirow{2}{*}{$\begin{array}{c}\text { Time Delay Before Movestop and Water } \\
\text { Pump }\end{array}$} & \multicolumn{2}{|l|}{ Distance from Fire } & Average & \multirow{2}{*}{ Remarks } \\
\cline { 3 - 6 } & T1 & T2 & T3 & Distance & \\
\hline & & & & & \\
\hline & & & & & \\
\hline & & & & & \\
\hline & & & & & \\
\hline
\end{tabular}

\section{Obstacle Avoidance Subsystem}

The components involved in this subsystem are the ultrasonic sensor, Servo Output, and the Manoeuvre Output. When an obstacle is detected, the microcontroller instructs the Manoeuvre Output to stop, then tells the Servo Output (which carries the ultrasonic sensor) to look left and right to find a clear path. The microcontroller further commands the Manoeuvre Output to turn in the direction of the clear path. However, when there is none, the microcontroller will instruct the Manoeuvre Output to move further backwards.

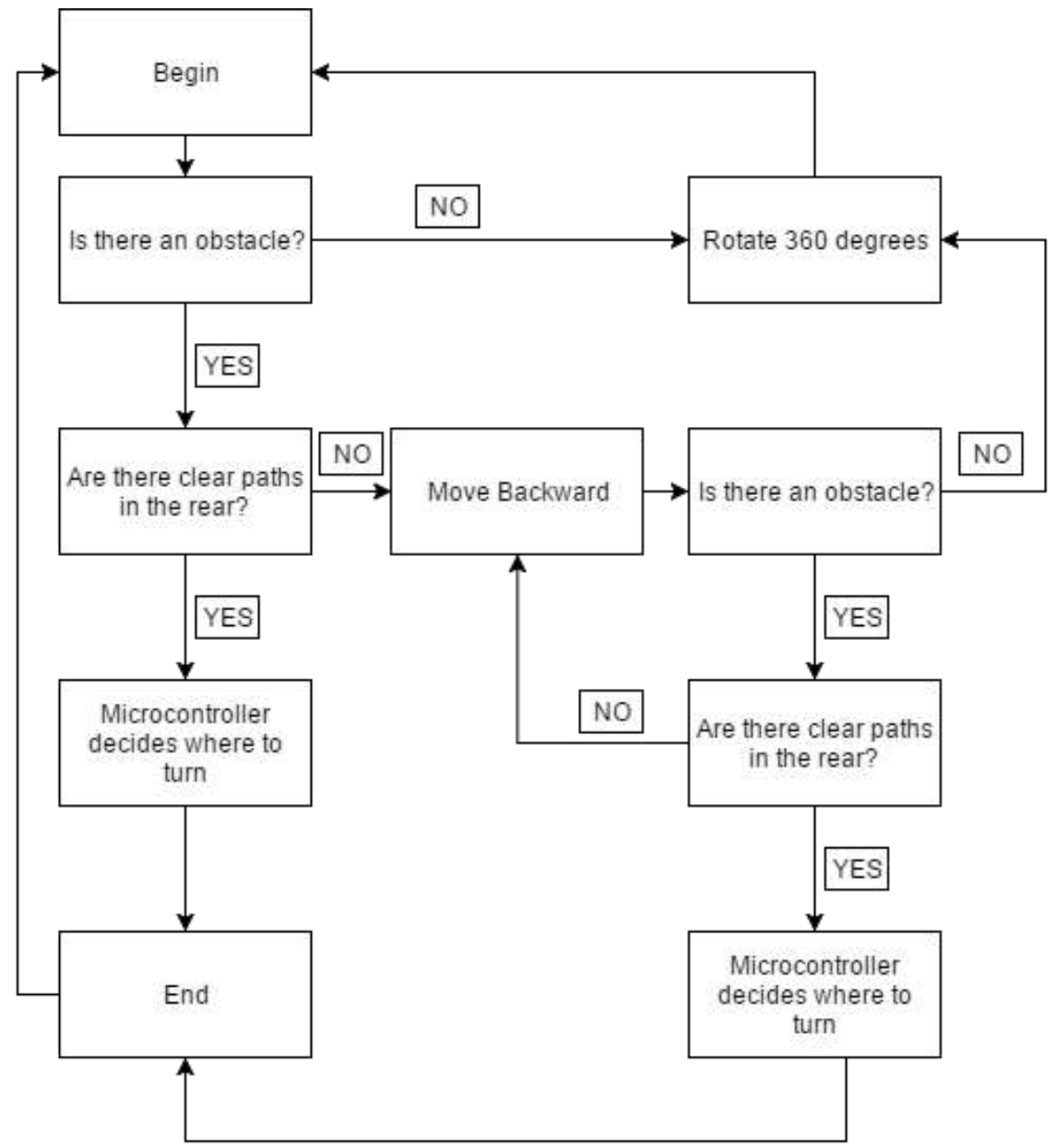

FIGURE 14.0 OBSTACLE AVOIDANCE SUBSYSTEM LOGIC DIAGRAM 


\section{Alarm Subsystem}

The sensors involved in this subsystem are the flame and smoke sensors. When flame or smoke is detected, the microcontroller commands the Alarm Output to activate, this means that the piezo speaker will start buzzing, the LED light will turn on and the GSM module will start sending SMS.

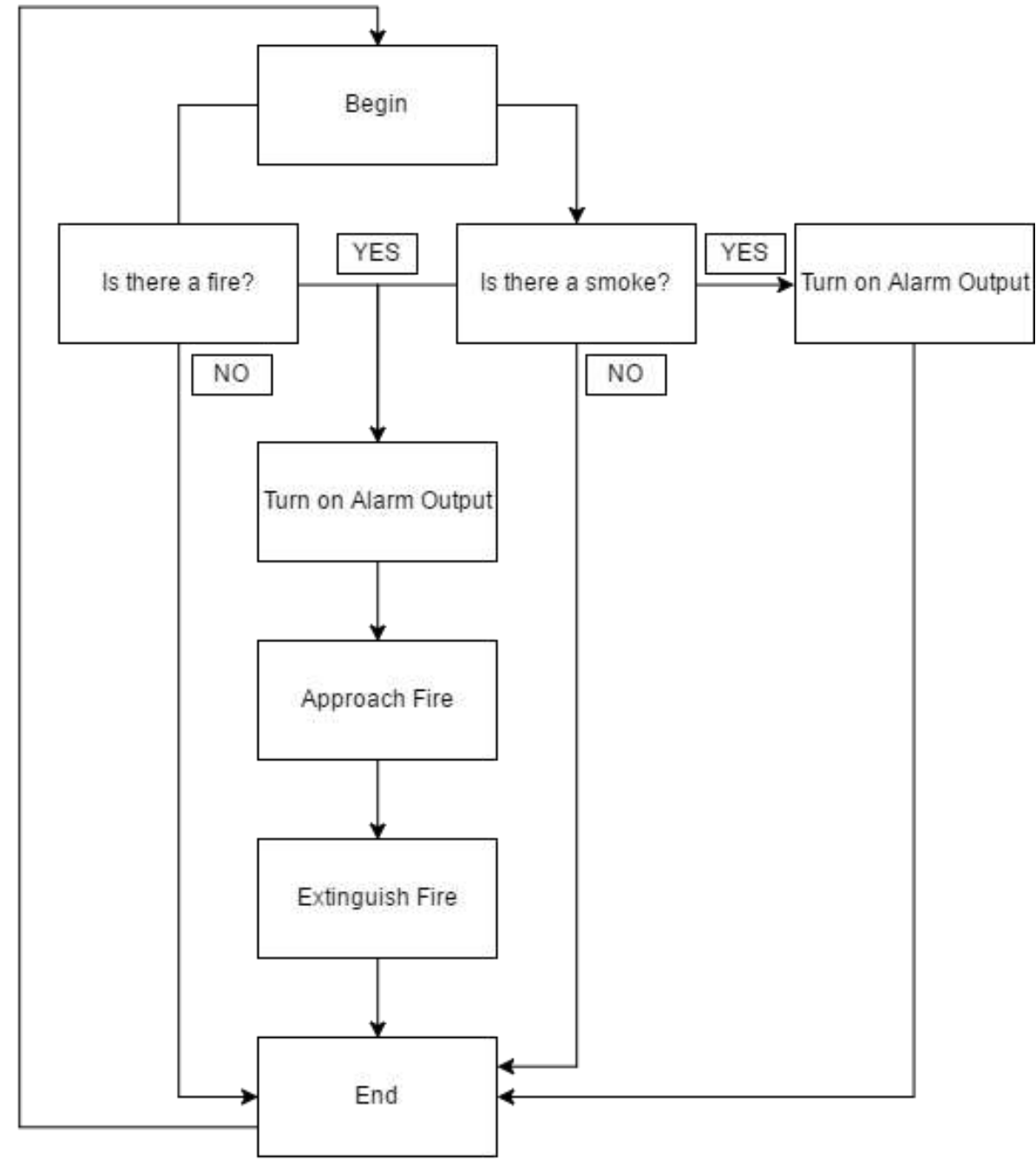

FIGURE 15.0 ALARM SUBSYSTEM LOGIC DIAGRAM

TABLE 2.0 DATA FOR SYSTEM RESPONSE TO FLAME USING FLAME SENSOR

\begin{tabular}{|c|c|c|c|c|c|c|c|c|c|c|c|c|c|c|c|}
\hline \multirow[t]{2}{*}{$\begin{array}{c}\text { Time } \\
\text { (seconds) }\end{array}$} & \multicolumn{3}{|c|}{ Flame Sensor } & \multicolumn{3}{|c|}{ Alarm } & \multicolumn{3}{|c|}{$\begin{array}{c}\text { LED } \\
\text { (Red, White) }\end{array}$} & \multicolumn{3}{|c|}{ SMS } & \multicolumn{3}{|c|}{$\begin{array}{c}\text { Water } \\
\text { Bombardment/Fire } \\
\text { Extinguished }\end{array}$} \\
\hline & T1 & $\mathrm{T} 2$ & T3 & T1 & $\mathrm{T} 2$ & T3 & $\mathrm{T} 1$ & $\mathrm{~T} 2$ & T3 & T1 & $\mathrm{T} 2$ & T3 & T1 & $\mathrm{T} 2$ & T3 \\
\hline & & & & & & & & & & & & & & & \\
\hline & & & & & & & & & & & & & & & \\
\hline & & & & & & & & & & & & & & & \\
\hline
\end{tabular}




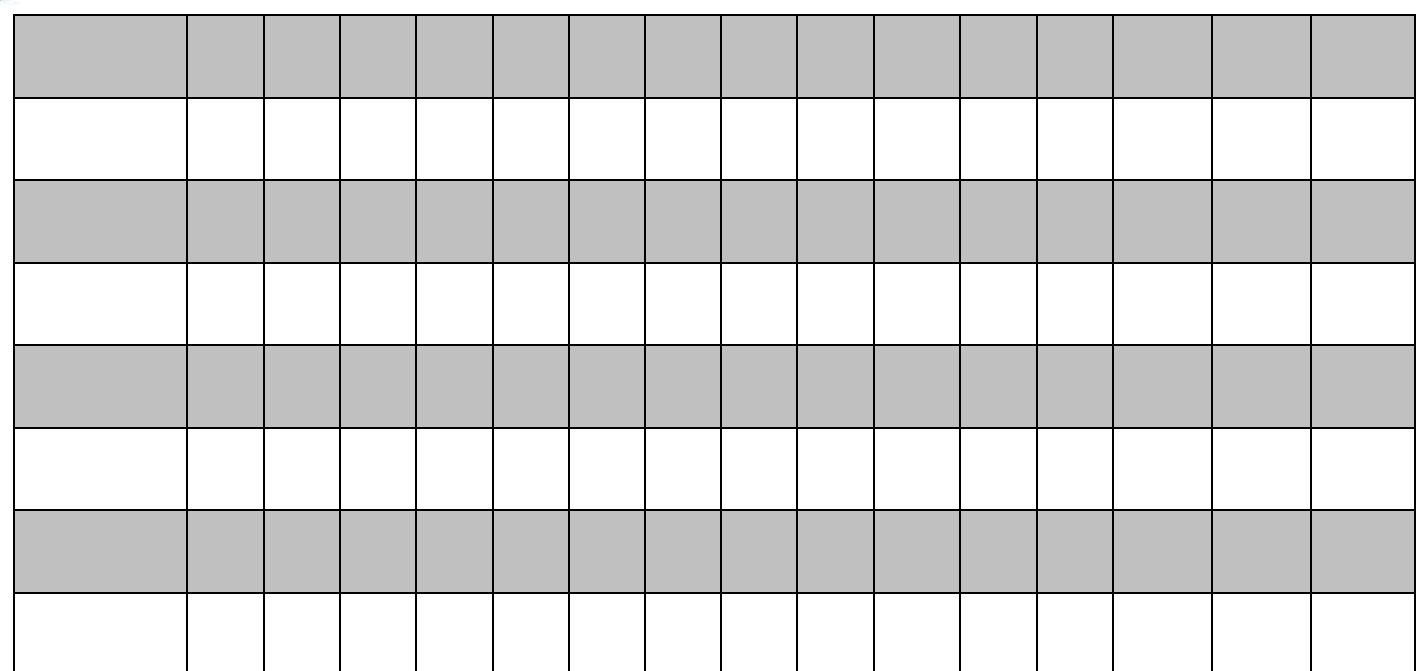

Legend: Check $(\checkmark)$ - Flame is Detected, Extinguished, and SMS

Red LED $(\checkmark)$, White LED (x)

\section{System Design}

Arduino Mega 2560 uses "Arduino Language" for its codes, which is similar to $\mathrm{C}++$. Integrating all subsystems, the team came up with the following logic flow:

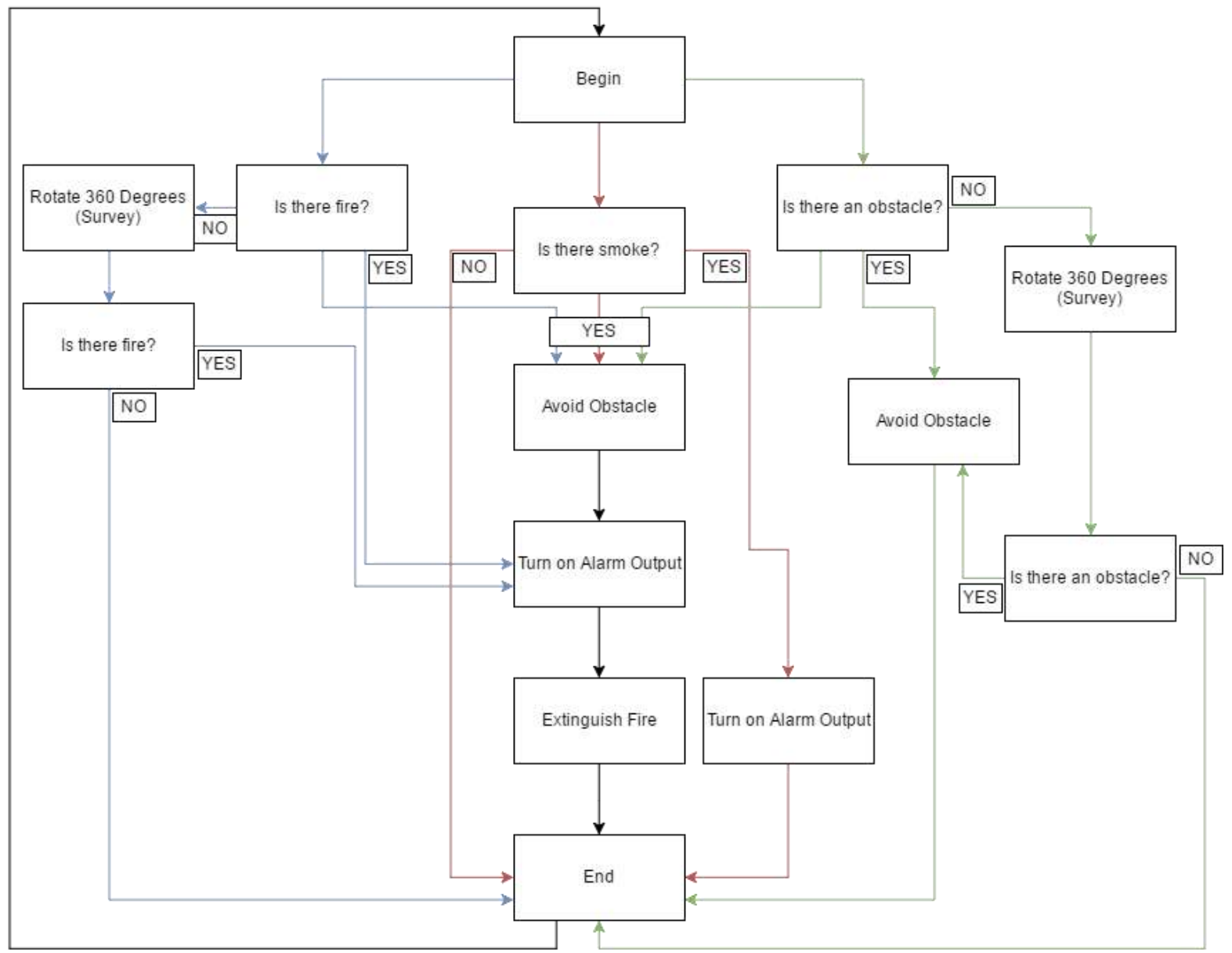

FIGURE 16.0 LOGIC FLOW 


\section{Testing}

Testing the robot was the most time consuming phase of the project because each module had to be tested separately before being integrated one after the other.

The first test was done with the positioning and wiring of the motors to see if all rotated in the same direction when the wires are placed as they are. Then was the integration of the microcontroller and motor driver to see if we can manage to make the robot turn with the program that the researchers wrote. The sensors were then added to give sources of input data that the microcontroller can work with to create decisions. Next was the mini water pump which we programmed to turn on only when fire is in its direct field of vision which also causes the motors to a stop. The same concept was applied to LED lights and piezo speaker that served as an audio-visual alarm. Last component to be integrated, simply because of their complexity were the smoke sensor and GSM module. The GSM module was programmed to send text messages to a receiver once smoke, fire, or both are detected.

TABLE 3.0 TEST DESIGN ON THE OVER-ALL PERFORMANCE OF THE ROBOT

\begin{tabular}{|l|l|l|}
\hline \multicolumn{2}{|c|}{ OBJECTIVES } & \multicolumn{2}{l|}{ RESULT/ PERFORMANCE } \\
\cline { 2 - 3 } & Successful & \multicolumn{1}{c|}{ Failed } \\
\hline $\begin{array}{l}\text { Integrate DC motors and Servo Motors to other components and } \\
\text { serve as output }\end{array}$ & & \\
\hline Detect presence of smoke, set off alarm, send SMS & & \\
\hline Detect fire, set off alarm stop moving, extinguish fire, send SMS & & \\
\hline Detect obstacle, create decision on where to turn & & \\
\hline
\end{tabular}

\section{Results and Discussions}

TABLE 4.0 RESULTS OF TEST DESIGN ON THE OVER-ALL PERFORMANCE OF THE ROBOT

\begin{tabular}{|l|c|c|}
\hline \multicolumn{2}{|c|}{ OBJECTIVES } & \multicolumn{2}{c|}{ RESULT/ PERFORMANCE } \\
\cline { 2 - 3 } & Successful & Failed \\
\hline $\begin{array}{l}\text { Integrate DC motors and Servo Motors to other components and } \\
\text { serve as output }\end{array}$ & $\checkmark$ & \\
\hline Detect presence of smoke, set off alarm, send SMS & $\checkmark$ & \\
\hline Detect fire, set off alarm stop moving, extinguish fire, send SMS & $\checkmark$ & \\
\hline Detect obstacle, create decision on where to turn & $\checkmark$ & \\
\hline
\end{tabular}


The table above shows the results gathered from subsystem to subsystem. As seen in the table, it can be observed that the integration of DC motors, servo motors, to other components served as output was successful. This means that all inputs will be actuated by these components. Furthermore, the experimentation as tabulated shows the result of the alarm subsystems, fire extinguishing and obstacle avoidance subsystems were integrated correctly.

\section{Fire Extinguishing Subsystem}

The actual footage of fire fighting robotic system equipped with sensitive flame sensors, avoidance mechanism, alarm and SMS capability is shown in Figure 17.0 (a). It was significantly revealed that successful operation of the fabricated fire fighting robotic system with several functionality took place. Proper detection of fire in the installed flame sensor works efficiently as expected. Timely pumping of water was triggered was and the correct signal was sent by the sensor to the microcontroller. It is observed the autonomous fire fighting robotic system automatically stops the pumping of water right after the complete extinguishing of fire as shown in Figure 17.0 (b).
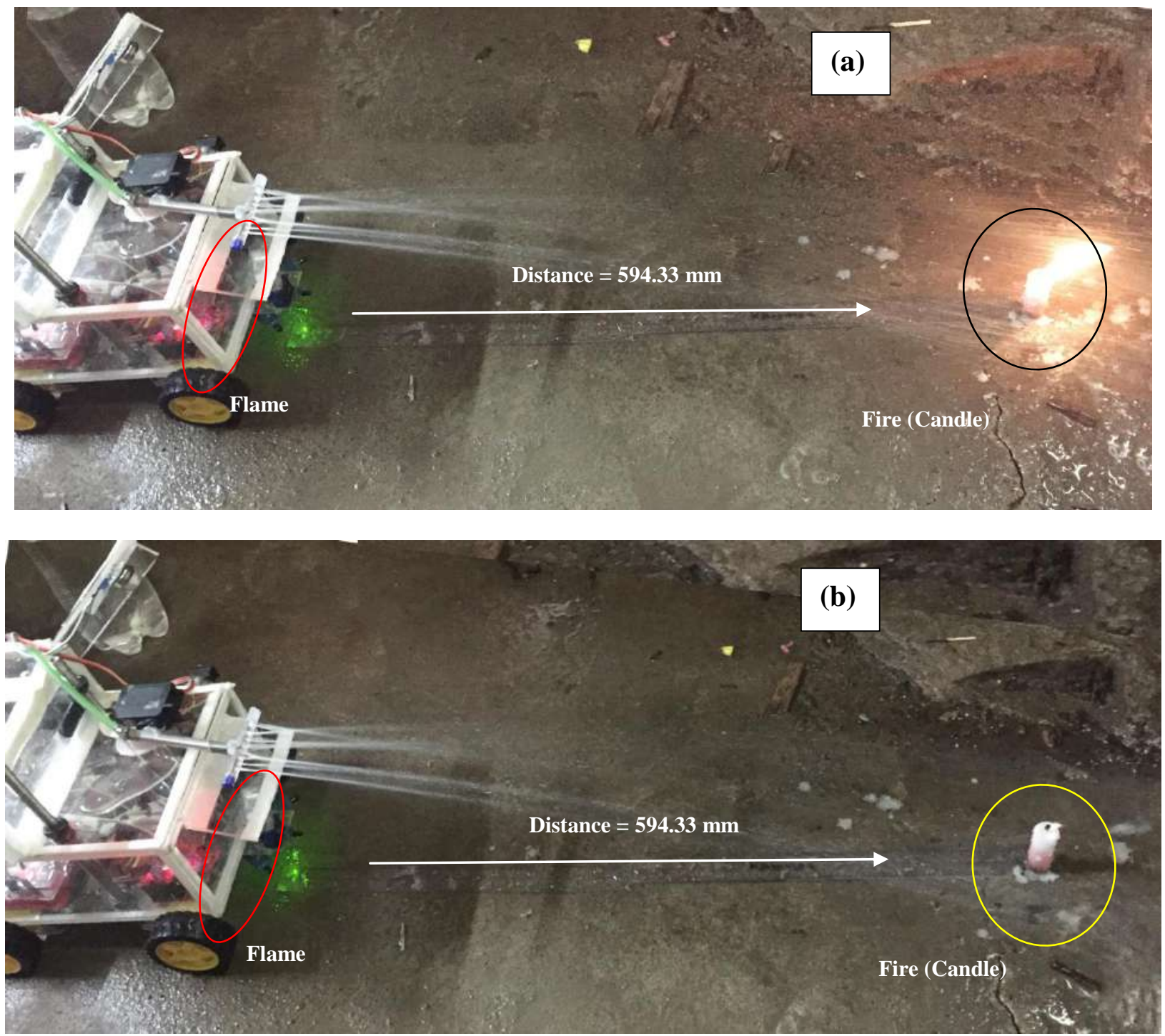

Figure 17.0 Actual footage of fire fighting robotic system equipped with sensitive flame sensors, avoidance mechanism, and alarm and SMS capability. (a) fire fighting robotic system in actual action detecting the existing of fire, (b) fire fighting robotic system in actual action extinguishing the presence of fire 
TABLE 5.0 EFFICIENCY TEST DESIGN FOR FIRE EXTINGUISHING

\begin{tabular}{|c|c|c|c|c|c|}
\hline $\begin{array}{c}\text { Time Delay Before } \\
\begin{array}{c}\text { Movestop and Water } \\
\text { Pump }\end{array}\end{array}$ & \multicolumn{3}{|c|}{ Distance from Fire } & $\begin{array}{c}\text { Average } \\
\text { Distance }\end{array}$ & Remarks \\
\hline $200 \mathrm{~ms}$ & $976 \mathrm{~mm}$ & $968 \mathrm{~mm}$ & $998 \mathrm{~mm}$ & $980.67 \mathrm{~mm}$ & Fire is too far \\
\hline $300 \mathrm{~ms}$ & $707 \mathrm{~mm}$ & $710 \mathrm{~mm}$ & $705 \mathrm{~mm}$ & $707.33 \mathrm{~mm}$ & Fire is too far \\
\hline $400 \mathrm{~ms}$ & $594 \mathrm{~mm}$ & $610 \mathrm{~mm}$ & $579 \mathrm{~mm}$ & $594.33 \mathrm{~mm}$ & Accurate \\
\hline $500 \mathrm{~ms}$ & $343 \mathrm{~mm}$ & $350 \mathrm{~mm}$ & $348 \mathrm{~mm}$ & $347 \mathrm{~mm}$ & Fire is too close \\
\hline
\end{tabular}

In order to observe systematic performance of the fabricated fire fighting robotic system, test of fire extinguishing delay was measured as listed in Table 4.0. It was revealed that it takes $400 \mathrm{~ms}$ before the movestop command was executed successfully and efficiently. This simply means that accuracy of response of the fabricated fire fighting robotic system took place. On the other hand, when the movestop is changed to shorter time (200 ms and $300 \mathrm{~ms}$ ), the fire fighting robotic system detected that fire was too far, thus the pumped water did not reach the target. Furthermore, when the movestop was set to $500 \mathrm{~ms}$, the fire fighting robotic system detected that the fire was too close, thus the pumped water was beyond the target. These results suggest that the accurate distance required for the time delay must be set at $400 \mathrm{~ms}$

TABLE 6.0 DATA FOR SYSTEM RESPONSE TO FLAME USING FLAME SENSOR

\begin{tabular}{|c|c|c|c|c|c|c|c|c|c|c|c|c|c|c|c|}
\hline \multirow{2}{*}{$\begin{array}{c}\text { Time } \\
\text { (milliseconds) }\end{array}$} & \multicolumn{3}{|c|}{$\begin{array}{l}\text { Flame } \\
\text { Sensor }\end{array}$} & \multicolumn{3}{|c|}{ Alarm } & \multicolumn{3}{|c|}{$\begin{array}{c}\text { LED } \\
\text { (Red, } \\
\text { White) }\end{array}$} & \multicolumn{3}{|c|}{ SMS } & \multicolumn{3}{|c|}{$\begin{array}{c}\text { Water } \\
\text { Bombardment/Fire } \\
\text { Extinguished }\end{array}$} \\
\hline & $\begin{array}{l}\mathrm{T} \\
1\end{array}$ & $\begin{array}{l}\mathrm{T} \\
2\end{array}$ & $\begin{array}{l}\mathrm{T} \\
3\end{array}$ & $\begin{array}{l}\mathrm{T} \\
1\end{array}$ & $\mathrm{~T} 2$ & T3 & $\mathrm{T} 1$ & $\mathrm{~T} 2$ & T3 & $\mathrm{T} 1$ & $\mathrm{~T} 2$ & T3 & $\mathrm{T} 1$ & $\mathrm{~T} 2$ & T3 \\
\hline 0 & $\checkmark$ & $\checkmark$ & $\checkmark$ & $\checkmark$ & $\checkmark$ & $\checkmark$ & $\checkmark$ & $\checkmark$ & $\checkmark$ & $\checkmark$ & $\checkmark$ & $\checkmark$ & $\checkmark$ & $\checkmark$ & $\checkmark$ \\
\hline 2 & $\checkmark$ & $\checkmark$ & $\checkmark$ & $\checkmark$ & $\checkmark$ & $\checkmark$ & $\checkmark$ & $\checkmark$ & $\checkmark$ & $\checkmark$ & $\checkmark$ & $\checkmark$ & $\checkmark$ & $\checkmark$ & $\checkmark$ \\
\hline 4 & $\checkmark$ & $\checkmark$ & $\checkmark$ & $\checkmark$ & $\checkmark$ & $\checkmark$ & $\checkmark$ & $\checkmark$ & $\checkmark$ & $\checkmark$ & $\checkmark$ & $\checkmark$ & $\checkmark$ & $\checkmark$ & $\checkmark$ \\
\hline 6 & & $\checkmark$ & $\checkmark$ & & $\checkmark$ & $\checkmark$ & $\mathrm{x}$ & $\checkmark$ & $\checkmark$ & & $\checkmark$ & $\checkmark$ & & $\checkmark$ & $\checkmark$ \\
\hline 8 & & & & & & $\checkmark$ & $\mathrm{x}$ & $\mathrm{x}$ & $\mathrm{x}$ & & & $\checkmark$ & & $\checkmark$ & $\checkmark$ \\
\hline 10 & & & & & & & $\mathrm{x}$ & $\mathrm{x}$ & $\mathrm{x}$ & & & & & & \\
\hline 12 & & & & & & & $\mathrm{x}$ & $\mathrm{x}$ & $\mathrm{x}$ & & & & & & \\
\hline 14 & & & & & & & $\mathrm{x}$ & $x$ & $\mathrm{x}$ & & & & & & \\
\hline
\end{tabular}




\begin{tabular}{|l|l|l|l|l|l|l|l|l|l|l|l|l|l|l|l|}
\hline 16 & & & & & & & $\mathrm{x}$ & $\mathrm{x}$ & $\mathrm{x}$ & & & & & & \\
\hline 18 & & & & & & & $\mathrm{x}$ & $\mathrm{x}$ & $\mathrm{x}$ & & & & & & \\
\hline 20 & & & & & & & $\mathrm{x}$ & $\mathrm{x}$ & $\mathrm{x}$ & & & & & & \\
\hline
\end{tabular}

Legend: Check $(\checkmark)$ - Flame is Detected, Extinguished, and SMS Red LED ( $\checkmark$ ), White LED (x)

To show the response of the Flame Sensor in Flame, the output of the flame sensor was connected as a digital output on the microcontroller, power supplies to the sensor and microcontroller was then switched on and the flame sensor turned on. The GSM module was then inserted by a Talk N' Text SIM, and the mobile number(s) to receive SMS were also entered. Without introducing flame, the sensor runs continuously. All indicators turned green, alarm system did not turned on, and no messages were sent implying that no flame was detected. However, when flame was introduced, the response time for the sensor, alarm, and sending of short text messages was recorded for 20 second. It was revealed that after the flame was introduced the flame sensor immediately detected the flame, 0-4 milliseconds in trial 1, and 0-6 milliseconds in trials 2 and 3 . The alarm was triggered by the presence of the flame, red LED turned on and messages were sent. When flame was extinguished in average time of 5.3 milliseconds, the flame sensor, and LED returned back to its normal condition. Thus, no messages were sent.

\section{Obstacle Avoidance Subsystem}

To test the efficiency of the installed ultrasonic sensor in the fire fighting robotic system, obstacle was placed along the pathway as shown in Figure 18.0. It was very apparent that successful avoidance of the fire fighting robotic system of the obstacle along the pathway was taking place. This was a manifestation that the installed ultrasonic sensor successfully sent signal to the microcontroller to avoid the obstacle efficiently.

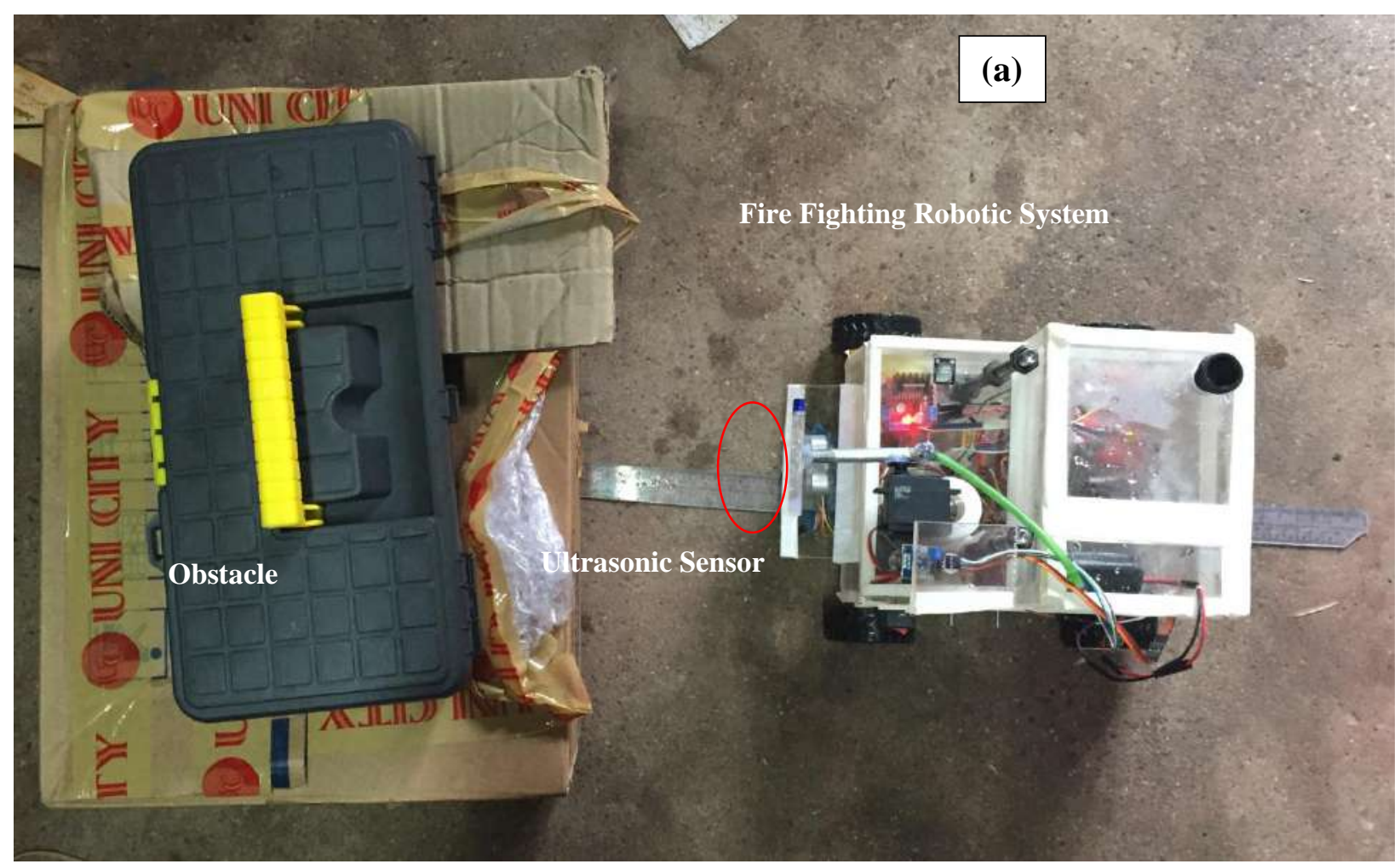




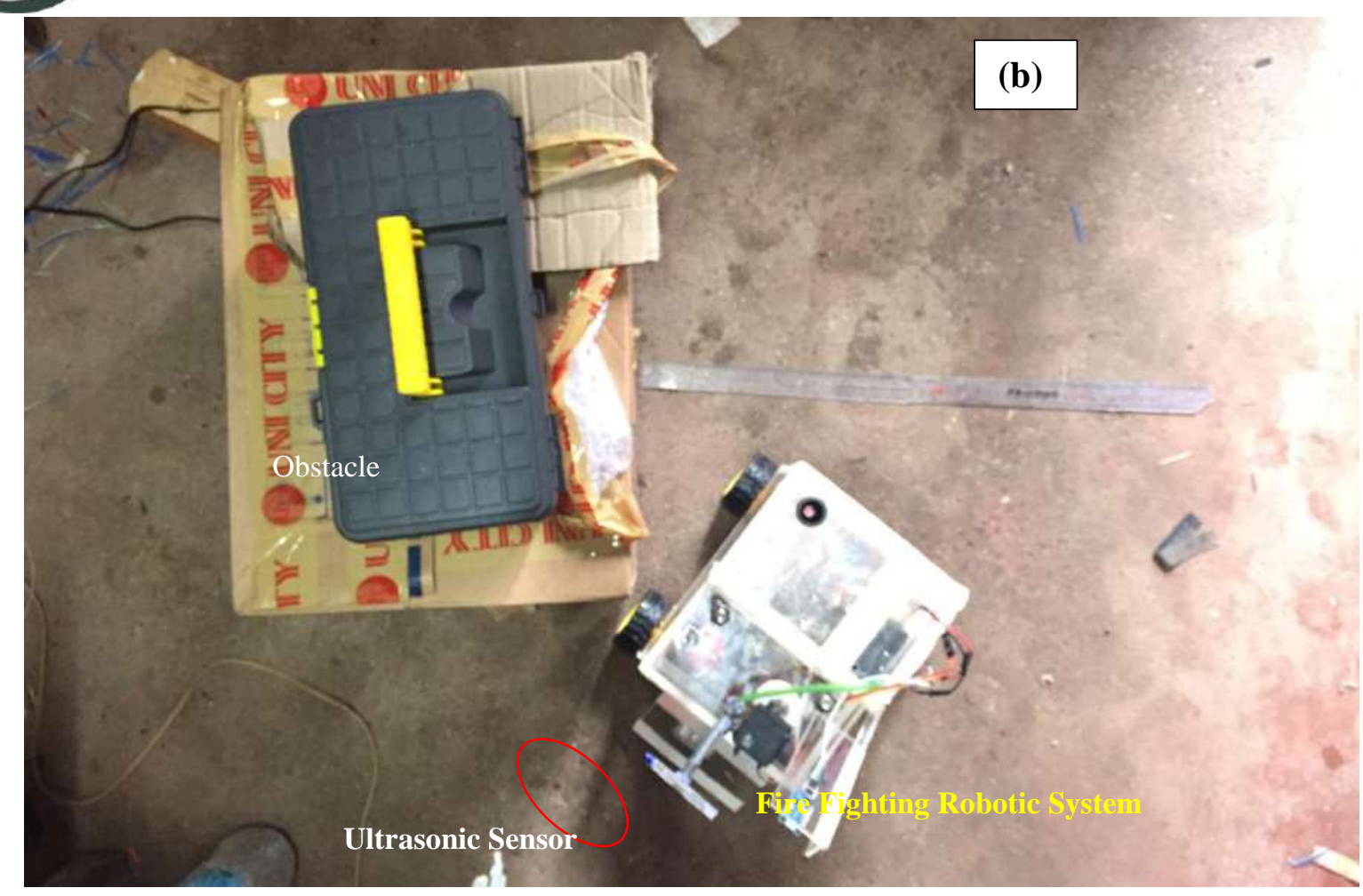

Figure 18.0 Actual footage of fire fighting robotic system showing the avoidance behaviour mechanism utilizing the ultrasonic sensor installed in the robotic system. (a) fire fighting robotic system with obstacle at around $1.0 \mathrm{~m}$ (b) fire fighting robotic system change direction in response to the obstacle in the pathway.

\section{Alarm Subsystem}

The successful footage of the fire fighting robotic system with activated SMS system sent to the concerned party as well as the activation of the alarm system and turned ON the red LED upon detection of flames and smoke is shown in Figure 19.0 (a) and (b).

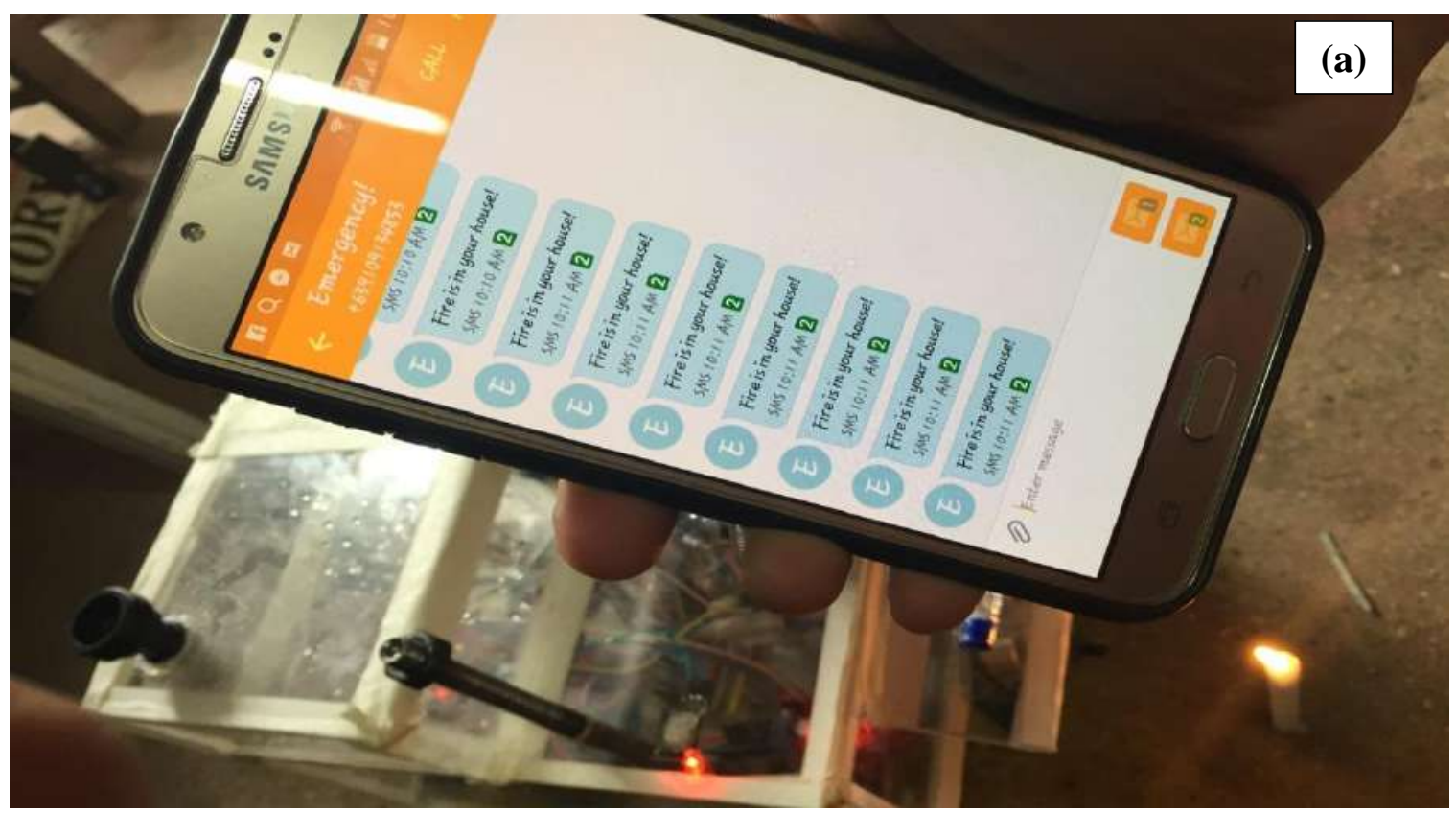


This is direct evidence that our robotic system efficiency sent SMS message to the concerned party upon detection of fire and smoke. Likewise, it is also observed that alarm was activated and red LED light turned ON upon the detection of fire and smoke suggesting that the sensitivity of our fabricated robotic system functions efficiently.

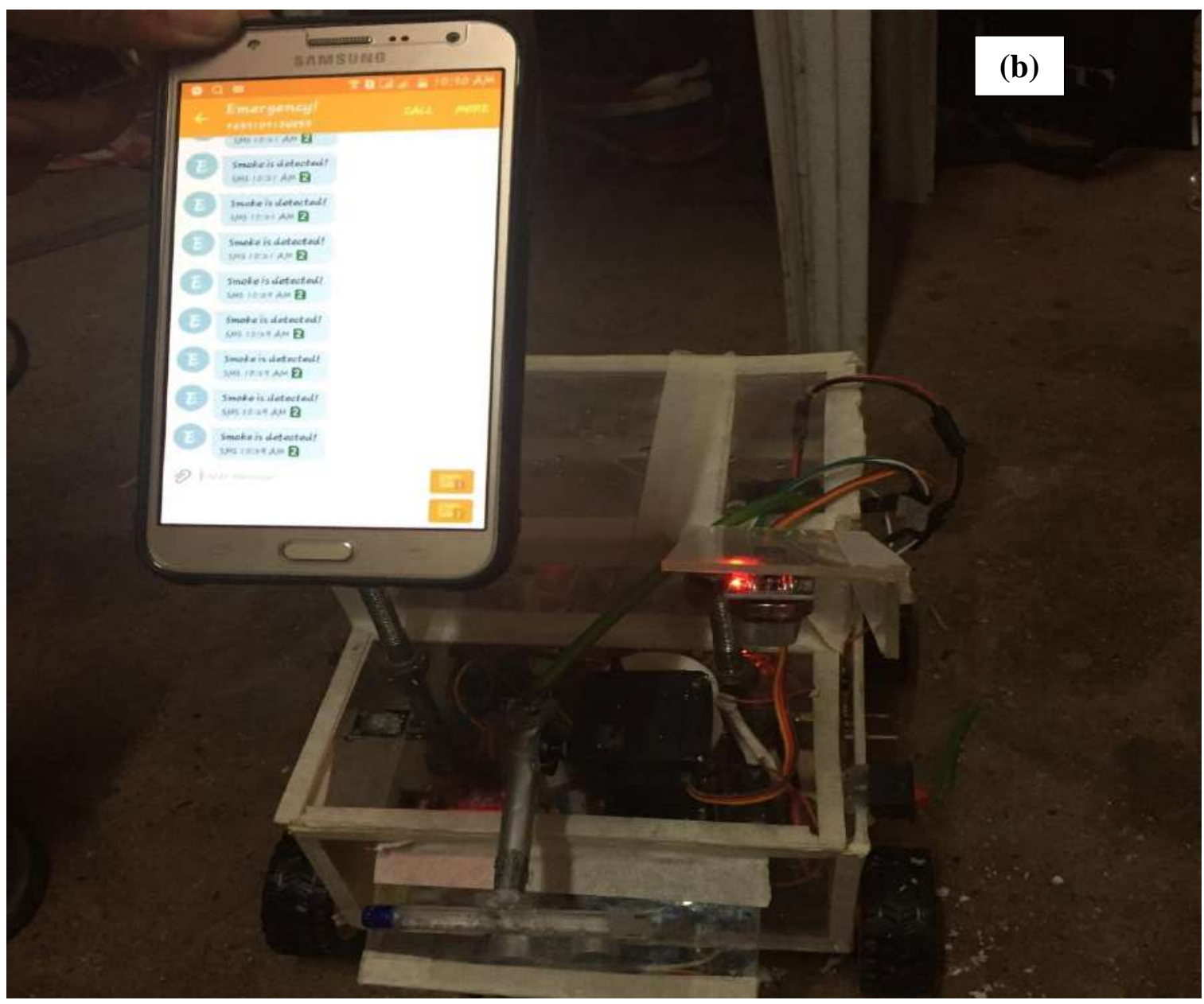

Figure 19.0 Actual footage of the fire fighting robotic system installed with automatic SMS activation upon the (a) fire and (b) detection as well the activation of the alarm system and turning ON of red LED upon detection of flame

\section{Summary, Conclusions and Recommendations}

\section{Conclusions}

A Fire Fighting Autonomous Robotic System Equipped with Sensitive Sensors for Fire Alarm and Detection, Avoidance Behaviour Mechanism and SMS Messaging Capability has been designed and fabricated. Complete extinguishing of smoke and fire was efficiently performed. Significant response of ultrasonic sensor installed in the robotic system was successfully recognized by the microcontroller which was manifested in the avoidance of the robotic system from the obstacle. Likewise, the alarm as well as the SMS message capability was successfully activated upon the detection of flame and smoke. The owner's mobile phone received a short text message warning them that fire has been detected. This simply suggests that the fabricated fire fighting autonomous robotic system was functioning effectively and efficiently. With the achievement of all the objectives of this research, it is 
concluded that the designed system is reliable and cost effective which should be employed in fire fighting operations to help limit the number of death and property loss in buildings and infrastructure.

\section{Recommendation}

The researchers would like to recommend the following:

1. To use flame-resistant materials and high spec components in the construction of the robot.

\section{References}

[1] Gregory M. Wernert, “Fire extinguishing system”, Sep. 1981.

[2] D. J. Pack., et al., "Fire-Fighting Mobile Robotics and Interdisciplinary Design-Comparative Perspectives" IEEE Transactions on Education, August 2004, 47, p. 369

[3] T. N. Satbhai. et al., "Fire Fighting Robot," April 2016, pp. 799.

[4] "Robot firefighter puts out its first blaze." 2017. New Scientist. Accessed December 3. https://www.newscientist.com/article/dn26920-robot-firefighter-puts-out-its-first-blaze/.

[5] "Projects on Fire Fighting Robotic Vehicle - Elprocus." ElProCus - Electronic Projects for Engineering Students. January 21, 2016. Accessed December 3.

https://www.elprocus.com/projects-on-flame-fighting-robotic-vehicle/

[6] Gerald Weed, Michael Schumacher, Shawn McVay, Jack Landes "PPPPokey the Fire-Fighting Robot. A Logical Design Using Digital and Analog Circuitry", May 111999.

[7] Myles Durkin, Kevin McHugh, Ryan Ehid, Brian Lepus, Stephen Kropp "Firefighting Robot. A Proposal." May 52008.

[8] "Rolly Firefighter Robot", William Dubel, Hector Gongora, Kevin Bechtold, and Daisy Diaz, Florida International University, Miami, 2003.

[9] “Fire Protection Robot”, Viet Do, Ryan Norder, and Ryan Spraetz, Moscow.

[10] "Autonomous Mobile Robot: Recognize and Response to fire” by Nik Md Hafizul hasmi B Md Suhaimi

[11] Angus, M. (2002). The Intelligent Fire Alarm. School of Information Technology and Electrical Engineering University of Queensland.

[12] John , H. K. (1997) Smoke Movement in Buildings. Fire Protection Handbook. 18th edition. NFPA 


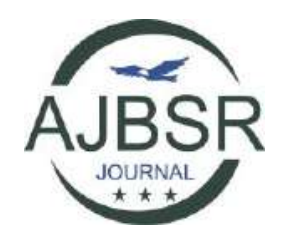

Asian Journal of Basic Science \& Research Volume 2, Issue 4, Pages 21-51, October-December 2020

Appendices

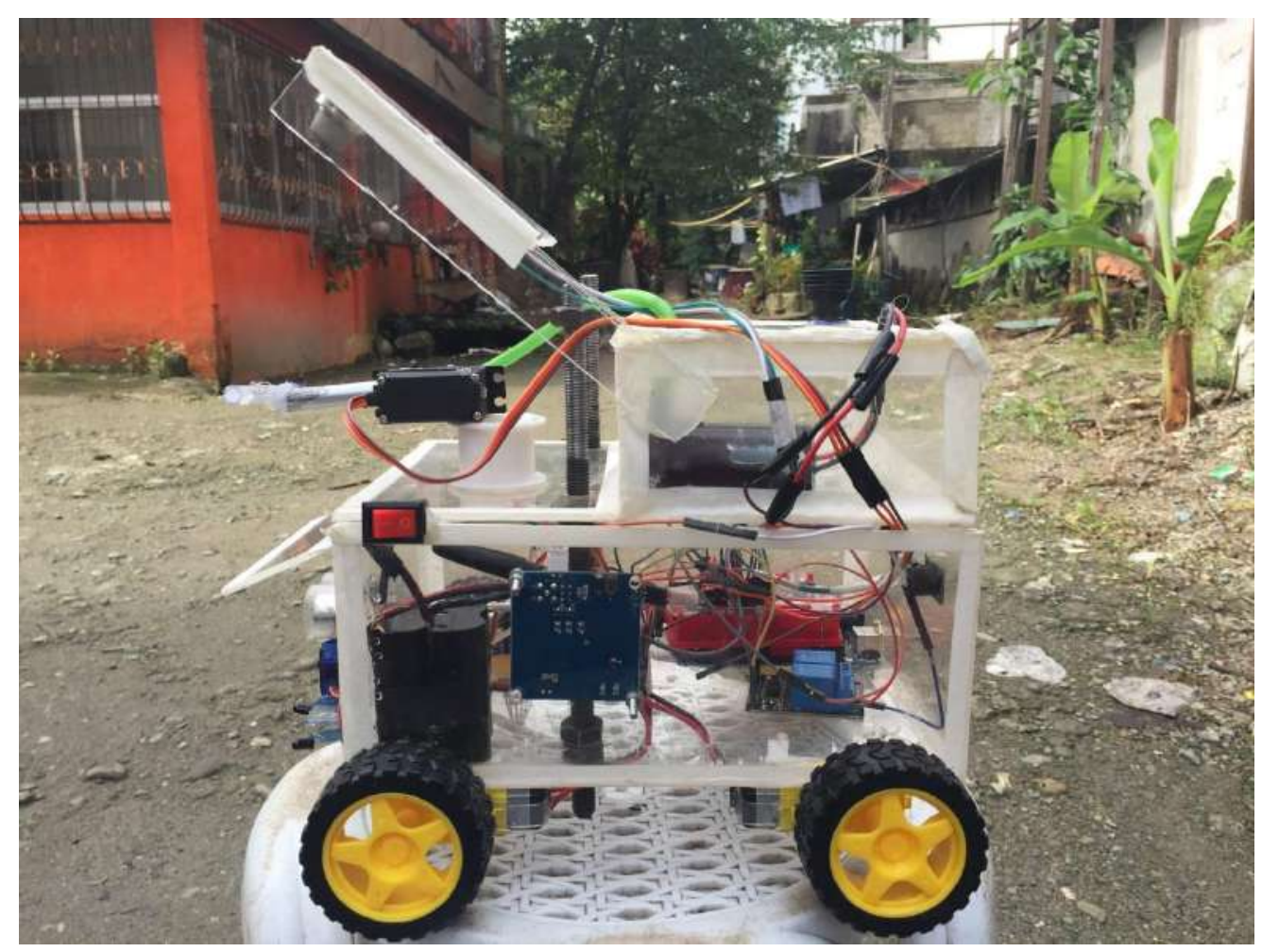

Figure 20.0 Side View of the Robot

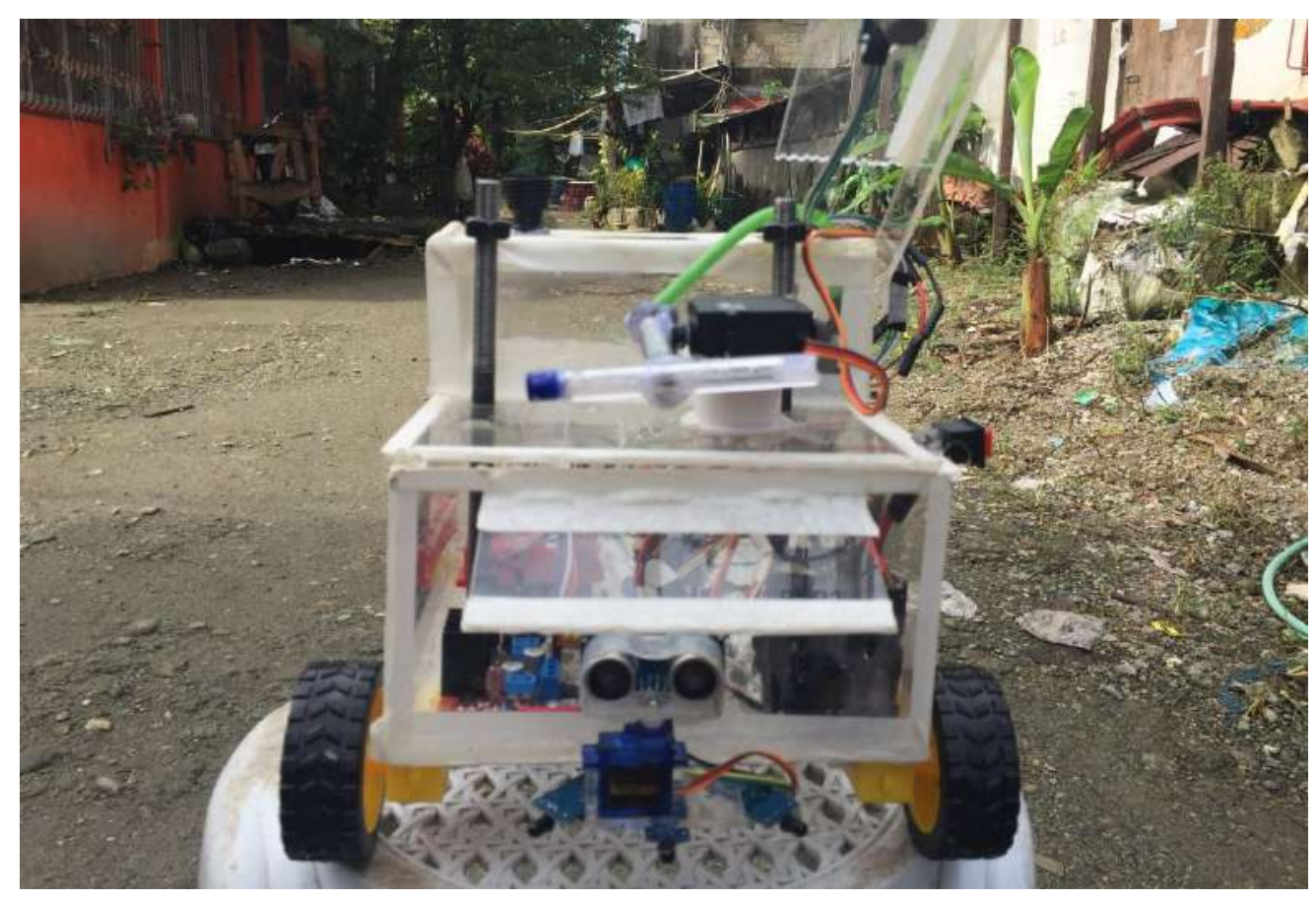

Figure 21.0 Front View of the Robot 


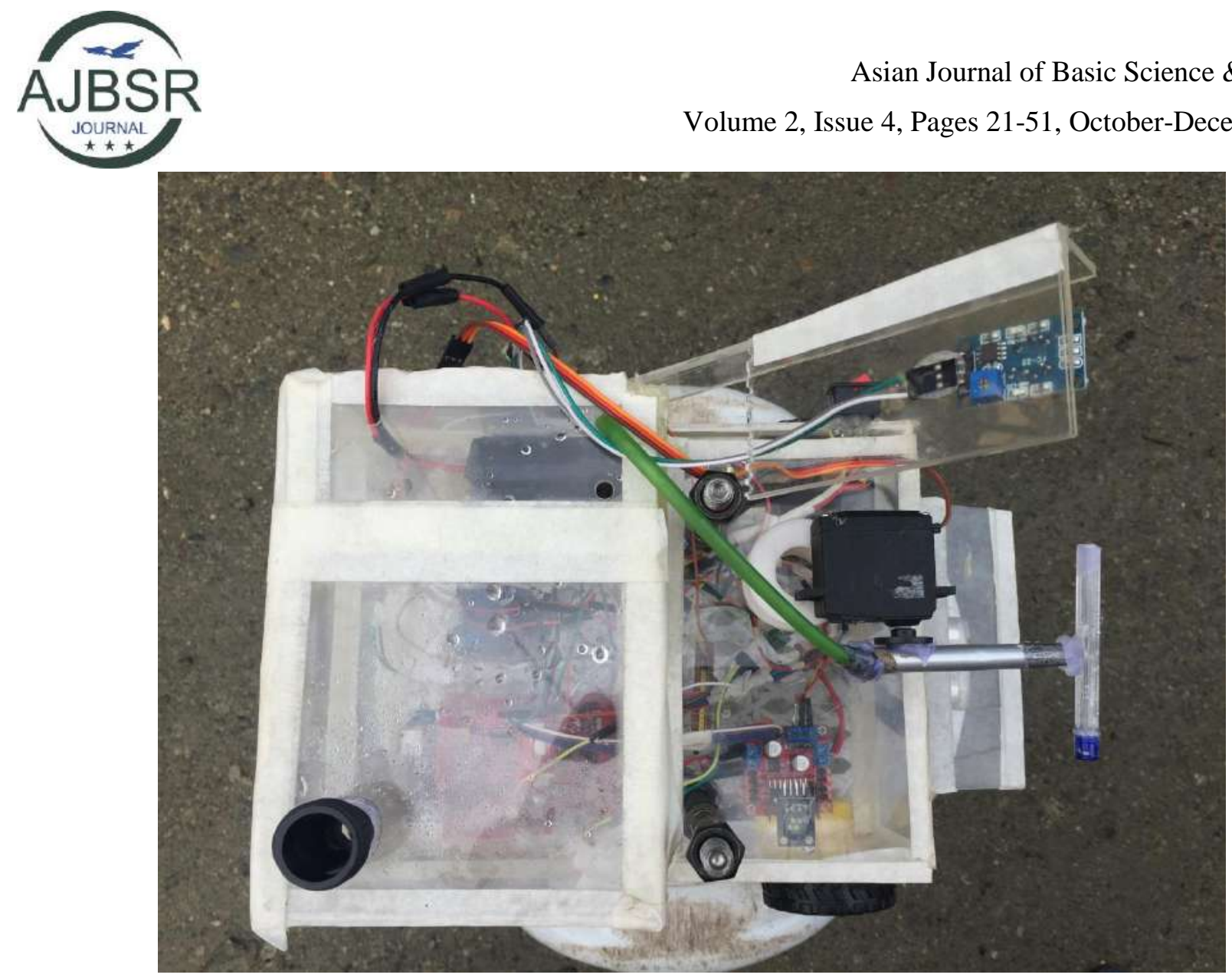

Figure 22.0 Aerial View of the Robot

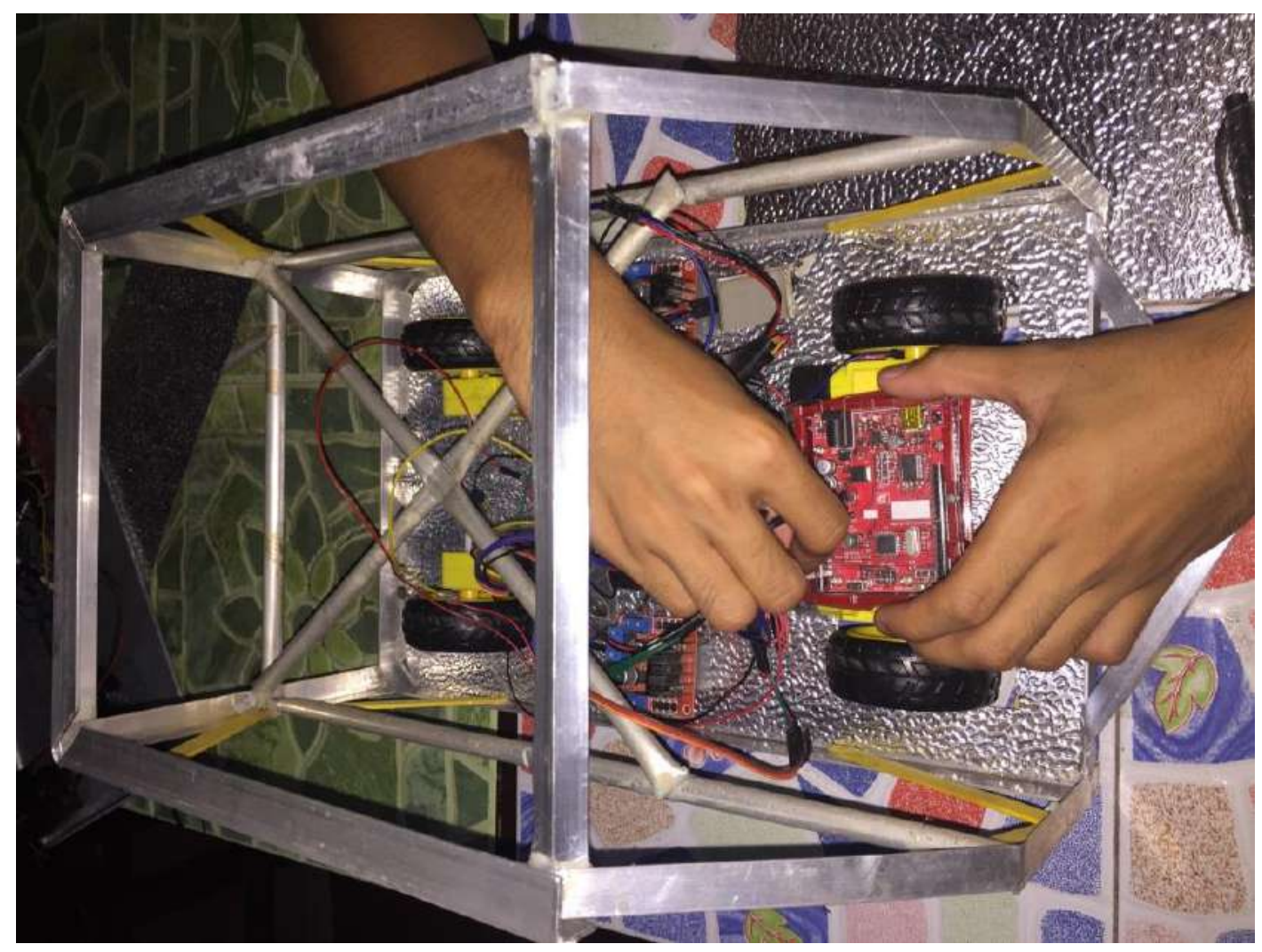

Figure 23.0 Examining the wire connections 